NBSIR 83-2682

\title{
Molecular Processes Affecting Mechanical Failure of Polymeric Materials
}

U.S. DEPARTMENT OF COMMERCE

National Bureau of Standarcs

Center for Materials Science

Polymer Science and Standards Division

Washington, DC 20234

Annual Report Covering the Period

August 1, 1982 -December 31, 1982

April 1983

Prepared for

Materials Science Division

Defense Sciences Office

Defense Advanced Research Project Agency

1400 Wilson Blvd.

Arlington, Virginia 22209 



\section{MOLECULAR PROCESSES AFFECTING MECHANICAL FAILURE OF POLYMERIC MATERIALS}

Bruno M. Fanconi

U.S. DEPARTMENT OF COMMERCE

National Bureau of Standards

Center for Materials Science

Polymer Science and Standards Division

Washington, DC 20234

Annual Report Covering the Period

August 1, 1982 -December 31, 1982

April 1983

\section{Prepared for}

Materials Science Division

Defense Sciences Office

Defense Advanced Research Project Agency

1400 Wilson Bivd.

Arlington, Virginia 22209

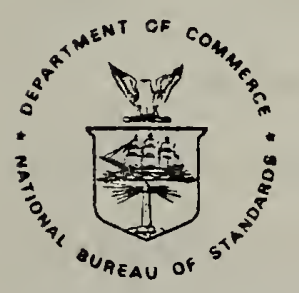

U.S. DEPARTMENT OF COMMERCE, Malcolm Baldrige, Secretary NATIONAL BUREAU OF STANDARDS, Emest Ambler, Director 

Molecular Processes Affecting Mechanical Failure of Polymeric Materials

\section{SUMMARY}

Preliminary observations have established correlations between the buildup in the concentration of molecular end groups and macroscopic failure in polymers. Current work has examined the effects of stress history, molecular weight and the dependence of the growth in end group concentrations with time during the course of a mechanical degradation experiment. In cyclic fatigue under uniaxial loading conditions the concentration of end groups was found to exhibit a sigmoidal dependence on the number of cycles. After an initial rapid rise to about $60 \%$ of its value at failure the number of chain.... scissions was observed to increase linearly until sample failure. Such a relationship holds promise as the basis of methods to predict mechanical failure. The effects of frequency, peak stress, and molecular weight have also been examined and are reported. INTRODUCTION

Polymeric materials are attractive for use in military applications due to their low density and cost as well as unique properties such as resistance to corrosive environments. However, the use of these materials has grown so rapidly in new applications that frequently their full exploitation, particularly in load bearing applications, is limited by inadequate knowledge and test methods relevant to long term performance in the use environment. Furthermore, techniques for nondestructive evaluation of polymeric materials have not been developed to the extent found for metals and ceramics because the processes affecting durability and performance are poorly understood. An improved 
understanding of molecular processes controlling the deterioration of mechanical properties would provide the basis for development of predictive models of long term performance, of methods to assess the remaining useful service life (nondestructive evaluation), and the development of new polymeric materials with improved long term performance.

The deterioration of mechanical properties has as its origin molecular processes affecting the chemical bonding arrangements. These processes may include disruption of hydrogen bonds and the van der Waals-type forces between polymer molecules, and scission of valence bonds that link the atoms together to form the polymer molecules. Catastrophic failure involves scission of the carbon-carbon bonds forming the polymer backbone. This process is thought to occur at the earlier stages of mechanical degradation but its importance has not been fully evaluated due to conflicting experimental data. In the model advanced by Zhurkov and co-workers (1) the backbone carbon-carbon bond scission (chain scission) is regarded as the precursor to microvoid formation from which cracks initiated leading to macroscopic failure. A critical aspect of this model, and one that needs verification, is that the free radicals produced as a result of the primary chain scission in turn initiate many additional chain scissions before recombinations form stable chemical species. The extent to which additional chain scission results from attack by free radicals is important to the design of polymeric materials with improved stability. The origins of molecular processes associated with mechanical degradation and fracture derive from the structures exhibited by polymers in the solid state. Two basic morphologies exhibited by crystallizable polymers are the spherulitic structure obtained by crystallization from the melt and the fiber structure associated with high degrees of chain orientation. The first is prevelant in crystallizable polymers prepared in such a way that there is little or no preferred chain 
orientation, and the second morphological type is formed by mechanical deformation either during or subsequent to solidification from the liquid state, or from solution. In Fig. Ia is shown an example of the underlying lamellar texture in which a single polymer molecule, represented by the meandering solid line, has both crystalline and disordered regions. The crystalline regions are confined to thin lamellae of the order of tens of nanometers in the chain direction, and since the molecular length is much larger, of the order of $10^{3} \mathrm{~nm}$, it is apparent that one molecule must fold back and forth in one lamella or span several lamellae.

Small angle neutron scattering experiments have confirmed the essential features of the model shown in Fig. la for semicrystalline polymers such as polyethylene. The lamellae are further organized into spherulitic structures such as shown in Fig. $1 \mathrm{~b}$ in which the lamellae radiate outward with the chain axis in the lamellae oriented tangentially to the radial direction. The loops and entanglements formed in the disordered interlaminar region are illustrated in Fig. 1b. An important morphological feature is the chain segments that bridge lamellae. The interlaminar region offers the path of least resistance to fracture, and as the spherulitic structure is deformed the predominant deformation on the local scale occurs in the interlaminar regions. In this manner the molecular segments in the disordered regions bear disproportionately large stresses that deform the molecular geometry and weaken some of the valence bonds between the backbore carbon atoms of the polymer molecule. This forms the incipient point for bond scission.

The technological importance of chain orientation is that materials with high tensile properties, Young's moduli and tensile strengths, exhibit high chain orientation and fibrillar texture. The polyaramids used as fiber reinforcements in advanced composites are an example of a highly oriented polytuer. 


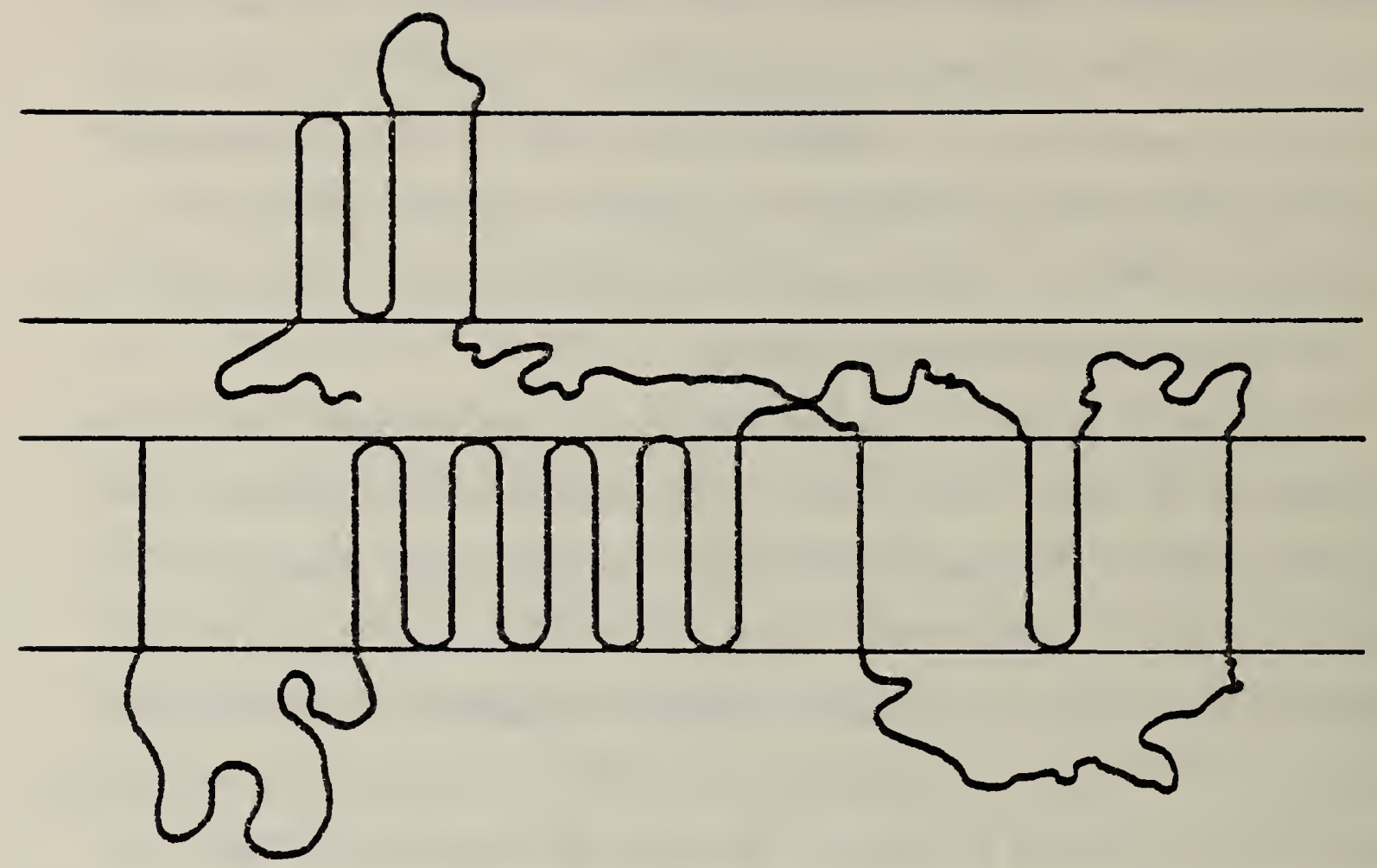

Figure la - Lamellar texture of semicrystalline polymers. 


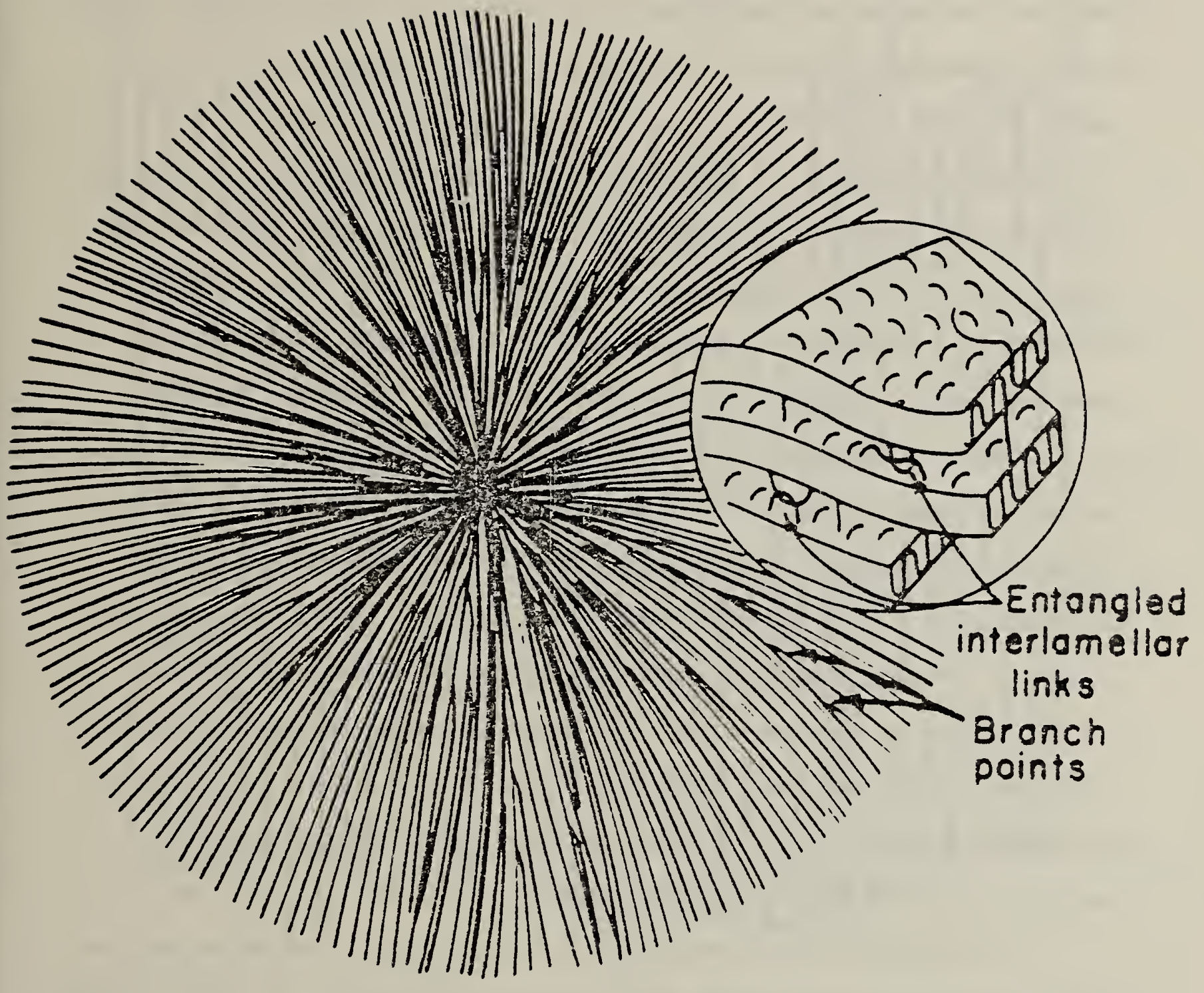

Figure lb - Spherulitic structure illustrating interlaminar links and entanglements. 
The fiber structure of a highly oriented polymer is shown in Fig. 2. In this case, lamellar texture is still evident for crystallizable polymers and an essential feature is again the molecular segments that bridge the 1amellae. The molecules comprising the interlamellar links are nearly extended so that subsequent deformation distorts the carbon-carbon backbond bonds leading to chain scissions.

At the molecular level the effect of the applied mechanical stress is to distort the equilibrium configuration, and in the case of valence bonds change the electronic distributions. The effect on the potential energy surface of the carbon-carbon bond is shown schematically in Fig. 3 where the potential energy is plotted against the interatomic distance. The states $A$ and $B$ refer to bonded and nonbonded states, respectively. In the absence of applied stress, top diagram, the barrier energy $G^{*} A B$ which must be overcome to cause chain scission is much larger than thermal fluctuations and the probability of a chain scission event is negligible. In the bottom diagram of Fig. 3 is depicted the situation when macroscopic stress is applied. In the presence of an applied stress the potential energy surface is distorted, moving the equilibrium bond distance to larger values and greatly reducing the barrier energy $G^{*}{ }_{A B}$. The result is that $G^{*} A B$ is much smaller which facilitates thermally activated bond scission.

As the potential energy surfaces of the vibrating atoms are determined by the electronic distributions the vibrational frequencies of modes involving carbon-carbon bond stretch should be affected by the applied mechanical stress. For some polymers investigated, most notably polypropylene, it has been observed that vibrational frequencies associated with motions of the backbone carbon atoms vary linearly with applied mechanical stress $(2,3)$. In the kinetic theory of fracture the rate of bond rupture is given by

$$
v=N_{K}(k T / h) \exp \left(-G^{*} A B / k T\right) \exp (s B \sigma / k T)
$$




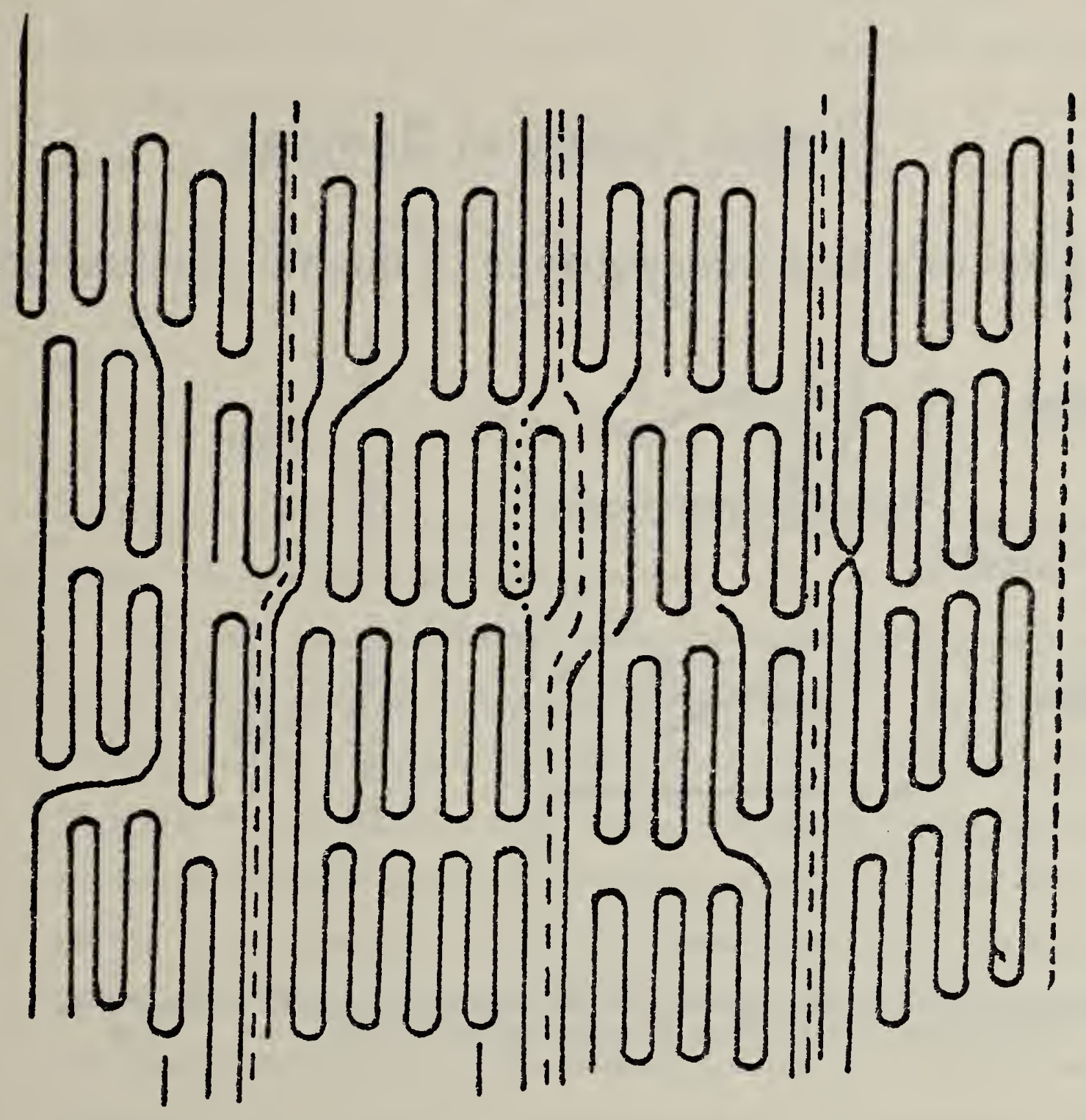

Figure 2 - Fiber morphology of uniaxially oriented polymers. 


\section{Kinetic Theory of Damage}

Bond fracture as a consequence of thermal fluctuations,

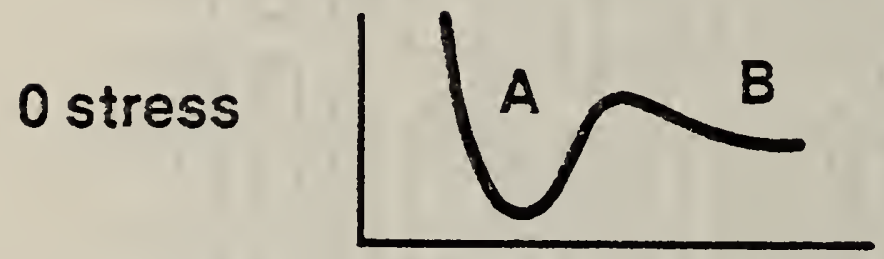

Bond loading

$\sigma$ stress
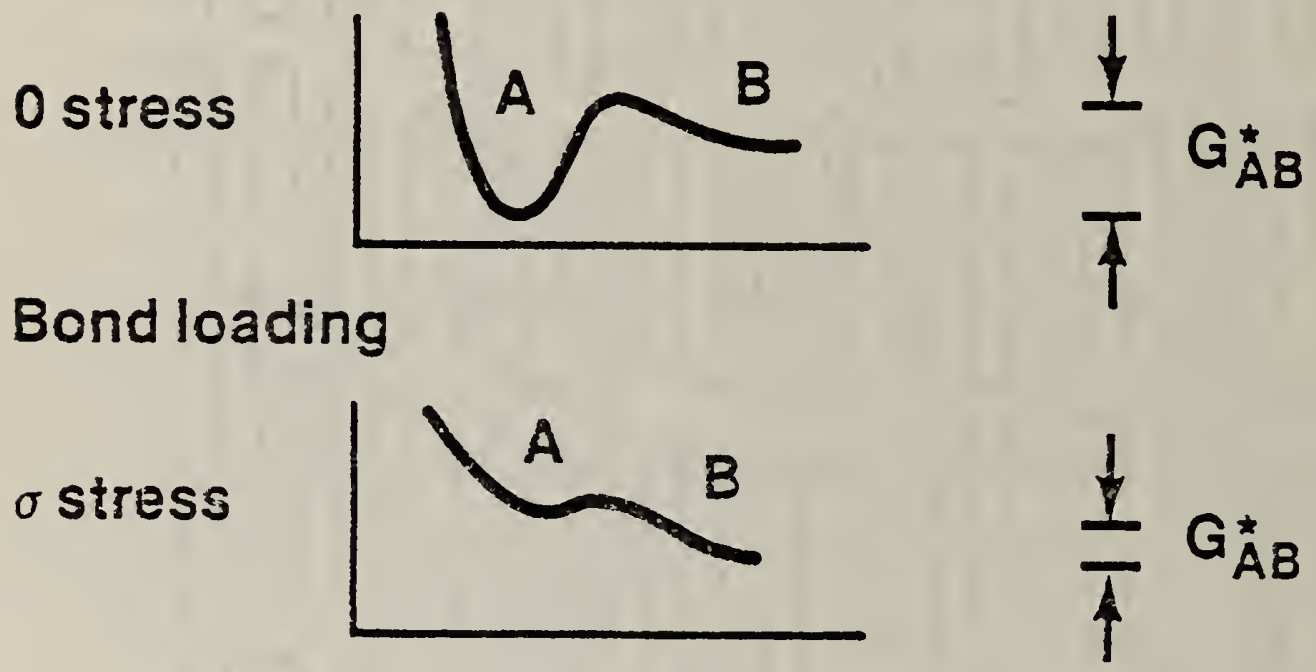

Figure 3 - Potential energy surfaces of the carbon-carbon bond: top curve, no applied stress; bottom curve, applied stress, $\sigma$. 
where $\mathrm{N}$ is the number of bonds, $k$ is the transmission constant, $k$ is the Boltzmann constant, $T$ is the temperature, $h$ is Plank's constant, $G * A B$ is the energy for activation of bond scission in the absence of applied stress, $\sigma$ is the applied stress, and $s \beta$ is the activation volume. If a critical number of chain ruptures, $\mathrm{N}_{\mathrm{c}}$, leads to macroscopic failure then the time to failure, $t_{f}$, can be identified as

$$
t_{f}=N_{c} / K_{A B}(\sigma)
$$

where

$$
K_{A B}=\kappa\left(\frac{k T}{h}\right) \exp \left(-G^{*}{ }_{A B}+s B \sigma\right) / k T
$$

According to equations (2) and (3) there is a logarithmic relationship between time-to-failure and applied stress.

The logarithmic relationship between time-to-failure and applied stress has been observed to hold over limited ranges of applied stress. For example, time-to-failure data as a function of applied tensile load for a linear polyethylene is shown in Fig. 4. The two linear regions are indicative of two modes of macroscopic failure: at low stresses brittle fracture dominates, whereas at higher stress failure is due to inhomogeneous deformation associated with neck formation and propagation. The downturn of the curves at the highest loadings can be attributed to a heating effect such that the average temperature of the specimens is higher than the ambient value. Increasing the temperature lowers the lifetime and hence the curves shift towards shorter lifetimes.

A useful representation of the stress-strain-time behavior of polymers is illustrated in Fig. 5 where the data are plotted for a linear polyethylene. The boundary of the fracture envelop gives the stress-straintime at failure (physical separation). Below the $\alpha$-line, brittle fracture dominates, between $\alpha$ and $\beta$, failure is by inhomogeneous deformation, and 


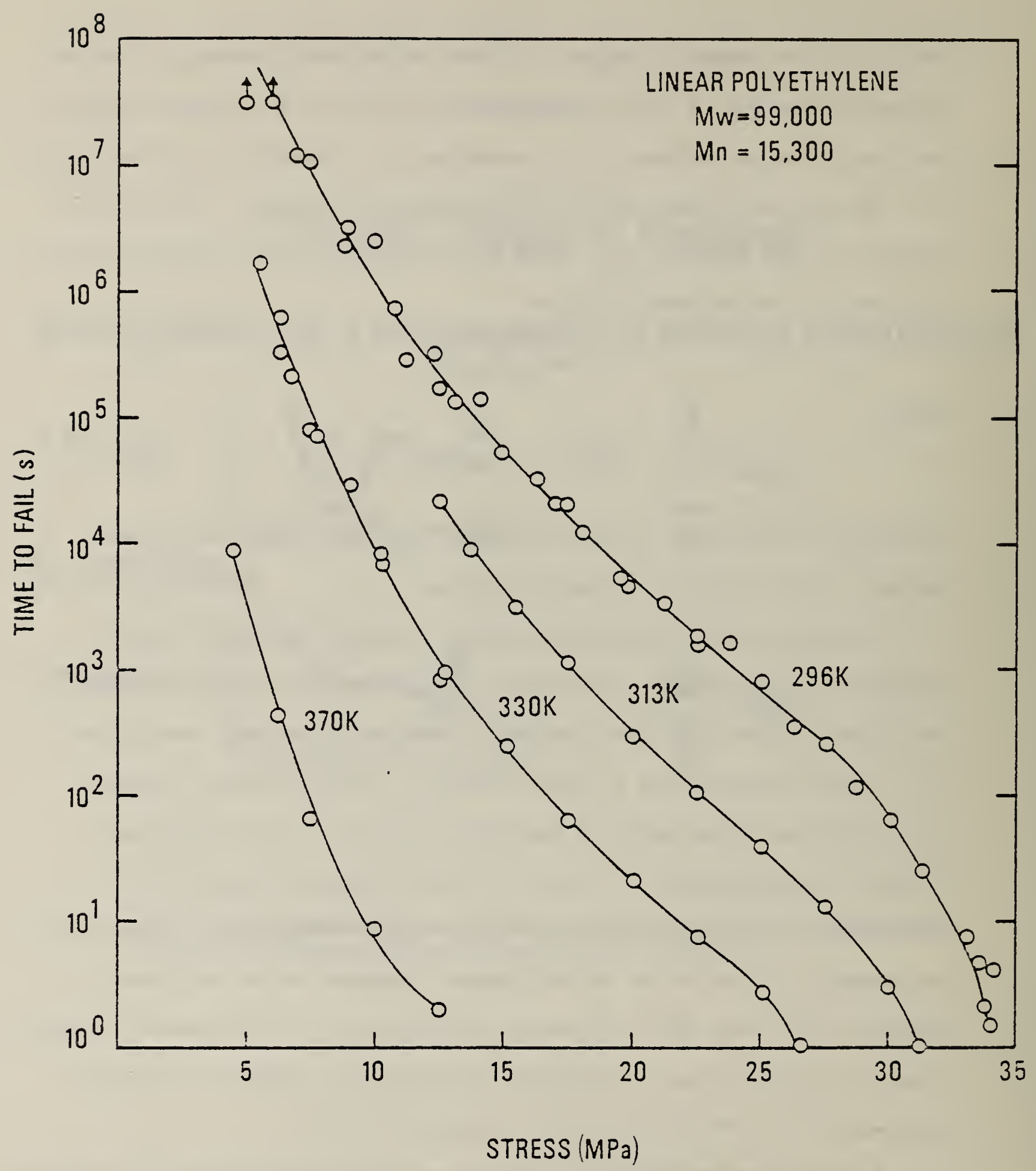

'Figure 4 - Time-to-failure data for a linear polyethylene in lniaxial load condition as a function of applied stress and temperature. 


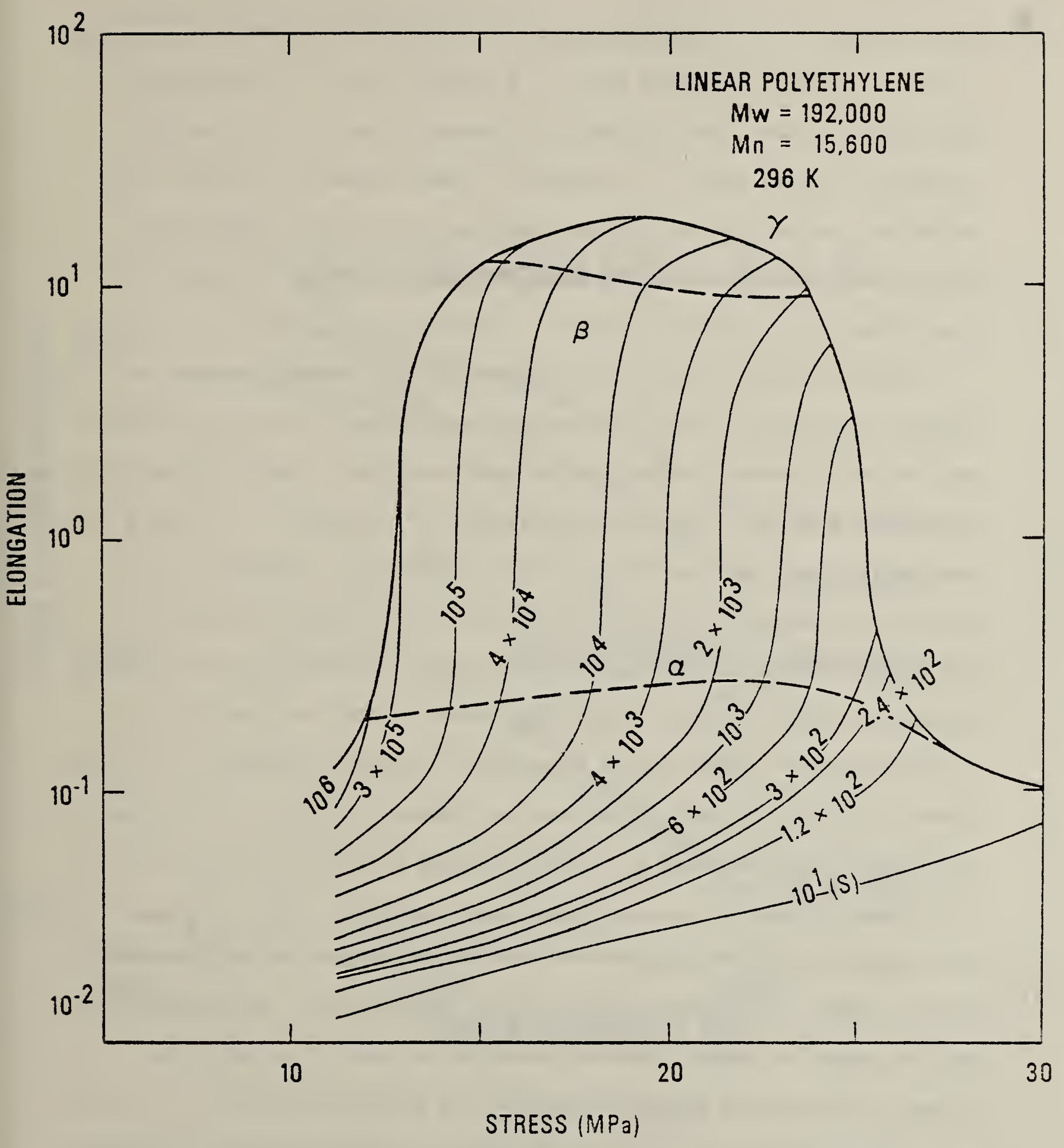

,Figure 5 - Fracture envalope of a linear polyethylene. a region, failure by brittle fracture; 3 region, inhomogeneous deformation; $\gamma$ region, brittle fracture of elongated specimens. 
between $\beta$ and $\gamma$, the elongated specimens again fail in a brittle-like fashion. Fracture envelopes serve as a useful means of characterizing macroscopic failure, and are useful in comparing results from analysis of molecular level events. The amount of chain scission associated with mechanical degradation may differ depending on the type of macroscopic failure mode operative. Furthermore, the manner by which the number of chain scissions accumulate to failure could vary.

Applied stresses that exhibit a periodic time dependence, such as cyclic fatigue, are another type of loading history relevant to in-use conditions, and for which laboratory studies have been conducted. Time-to-failure data on polyethylene (4) and poly(methymethacrylate) (5) subjected to stresses varying sinusoidally in time have indicated that neither cycle dependent nor accumulative damage failure are operative. In Fig. 6ab are compared the failure data for ultra high molecular weight polyethylene subjected to sinusoidal tensile loading. The dashed curve in Fig. 6 a gives the predicted failure behavior with frequency if failure occurred at a critical number of cycles. Clearly, this does not happen. In Fig. 6b are compared the observed failure times for fatigue loading with failure times predicted from times-to-failure data under dead load conditions. This comnarison indicates that damage leading to failure is not additive in terms of the fractional failure times determined by static loading experiments. We have examined how the number of chain scissions accumulate in cyclic loading in an attempt to understand damage accumulation in fatigue experiments. We have also determined the dependence of the number of chain scissions at failure with test frequency, peak stress level, and molecular weight. 


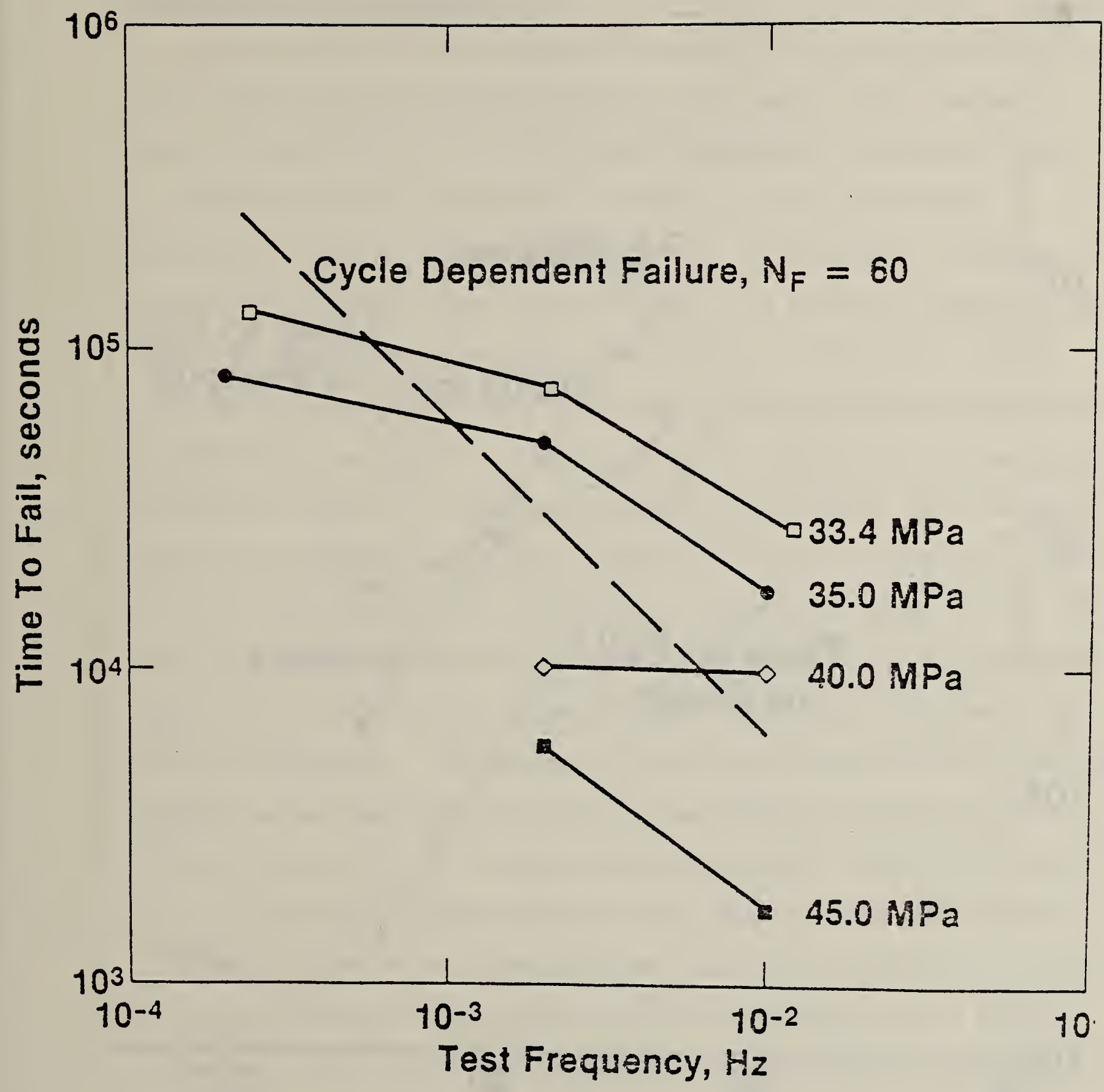

Figure $6 a$ - Time-to-failure data against test frequency as function of peak load. The dashed curve gives the predicted failure behavior if failure occurs at critical number of cycles. 


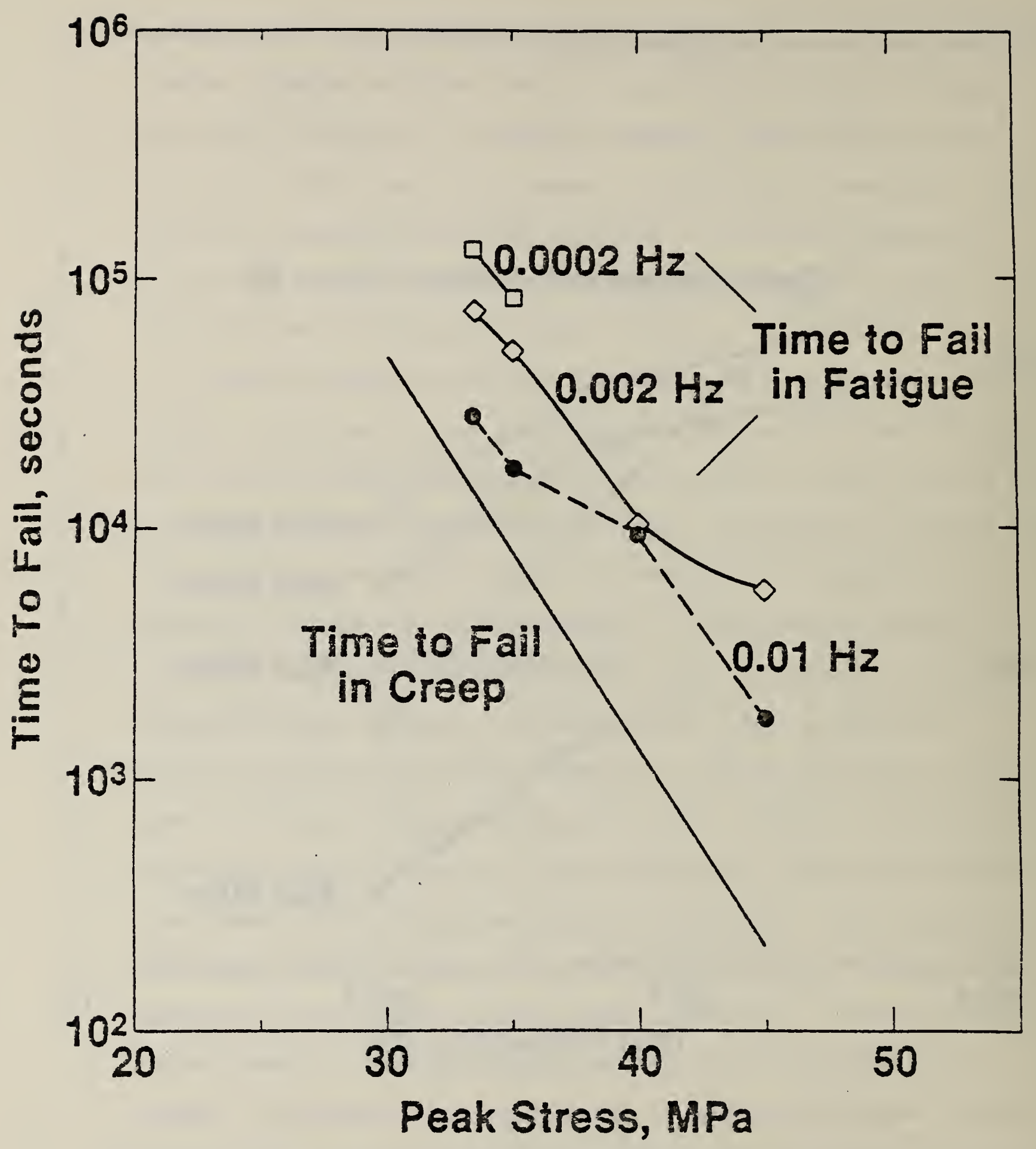

Figure 6b - Times-to- failure compared with predictions based on constant load data assuming the additivity of camage concept. 
MOLECULAR DAMAGE CHARACTERIZATION

The evidence for chain scission associated with mechanical degradation comes from three rather different types of experiments. The chemistry of chain scission is depicted in Fig. 7 for polyethylene. The initial rupture of the carbon-carbon backbone bond produces two unpaired electrons, or primary free radicals, one on either end of the ruptured chain. These molecular entities are highly reactive, but can be trapped by conducting the mechanical degradation at cryogenic temperatures. Electron spin resonance (ESR) has been used to determine the type and concentrations of free radicals produced during mechanical degradation. Fig. 8 a shows how the concentration of free radicals builds up during straining of nylon-6 fibers. Up to about $7 \%$ there is no detectible ESR signal, but the signal then rises slowly at first and more abruptly at higher strains until the specimen failure at about $14 \%$ strain. For most polymers ESR measurements must be carried out at cryogenic temperatures, therefore this technique is not applicable to polymers in most service environments. ESR spectra of polyethylene degraded under liquid nitrogen and held at low temperatures have been interpreted as arising from the primary radicals (6). As the PE specimens were slowly heated the ESR spectra changed and spectral analysis indicated the presence of the alkyl radical, $-\mathrm{CH}_{2} \mathrm{CHCH}_{2}-$, shown in the second reaction illustrated in Fig. 7 (6). In the absence of atmospheric oxygen this free radical decomposes into a primary radical and a vinyl terminated chain end. In the presence of $\mathrm{O}_{2}$ the reaction proceeds through a peroxy radical that can decompose into an aldehyde group and another oxygen containing free radical which may undergo further reactions to produce alkyl radicals. The important aspects of the free radical reactions shown in Fig. 7 are that the initial free radicals produced by chain scission of over stressed chains may initiate many additional chain 


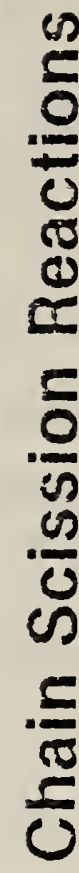

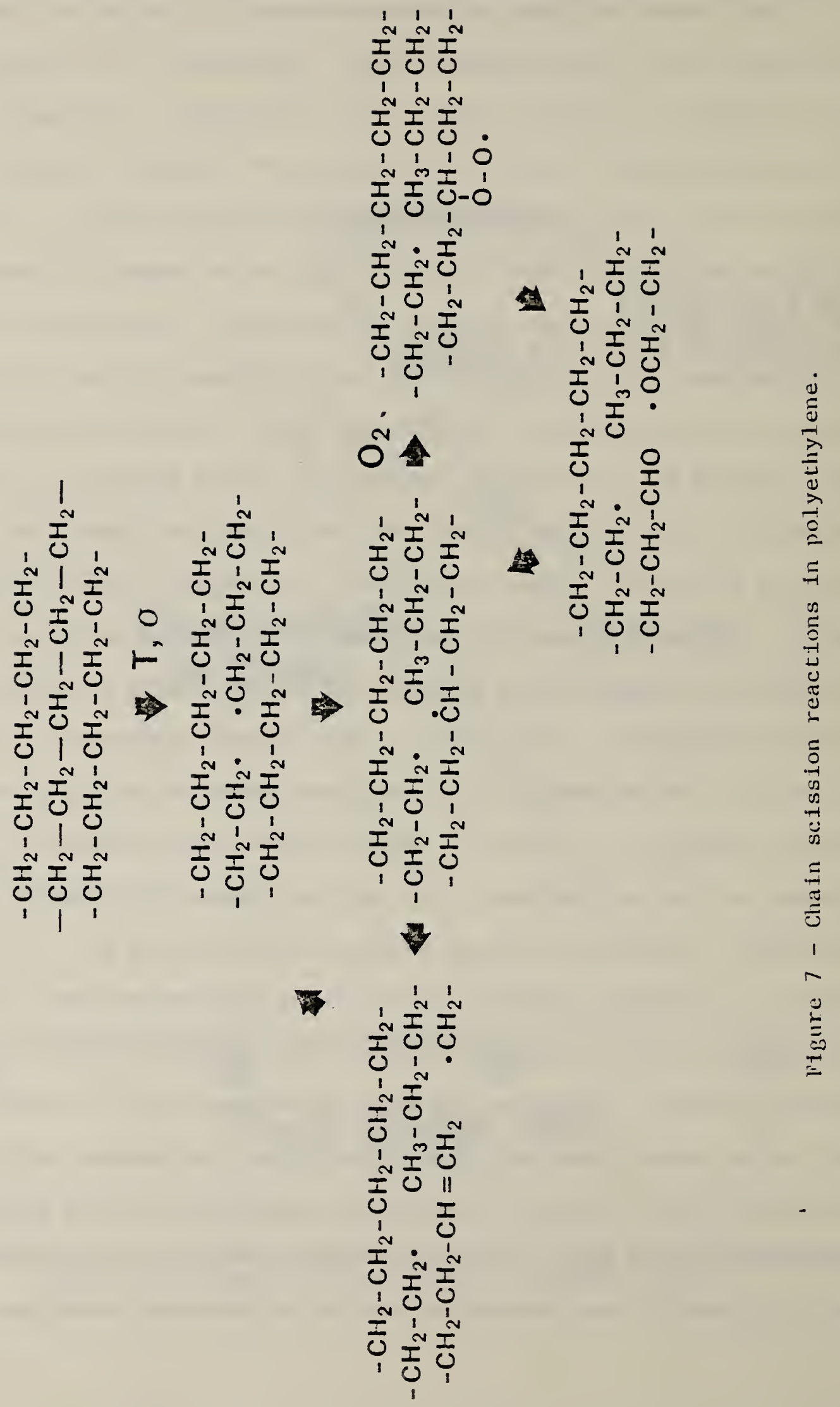




\section{Electron Spin Resonance}

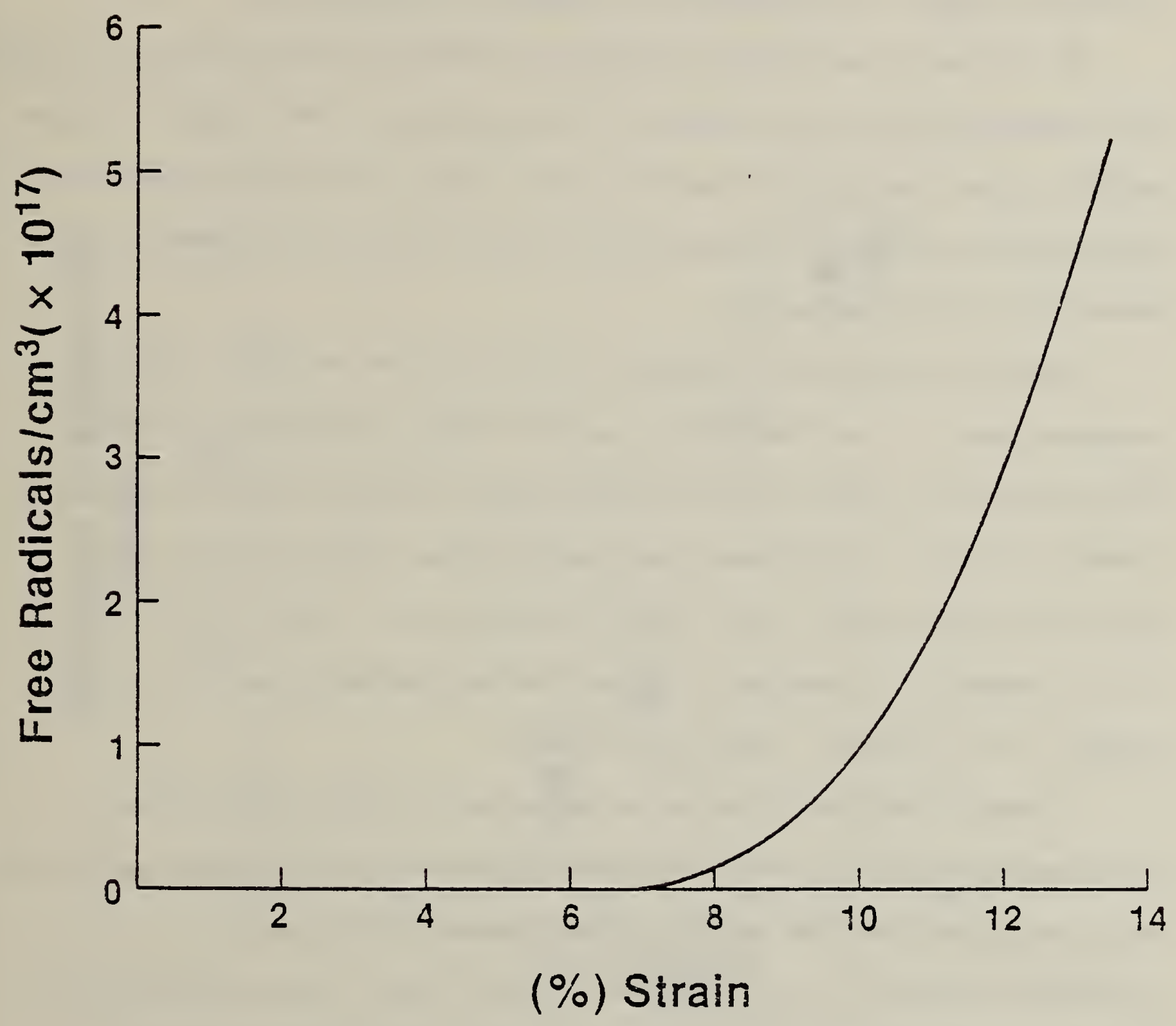

Figure $8 \mathrm{a}$ - Generation of free radicals in rylon-6 fibers by straining 
scissions, and in the process decrease the average length of the polymer chains, as well as generate new molecular end groups. Evidence for decrease in the average chain length comes from measures of molecular weight. Increases in the concentration of molecular end groups are determined by infrared spectroscopy. In Fig. $8 \mathrm{~b}$ is shown how molecular weight changes with strain in nylon-6 fibers. The behavior is similar to the ESR data.

The initial free radicals produced by mechanical excitation of CC bonds may recombined with no net changes in the structure. This event is rather unlikely since the overstressed chain will relax upon chain rupture further increasing the distance between the two free radicals and decreasing the probability of recombination.

Another mechanism is transfer of a proton from one side of the ruptured chain to the other which has the effect of generating two new chain ends, one of which is a vinyl end group $\left(\mathrm{R}-\mathrm{CH}=\mathrm{CH}_{2}\right)$ and the other one a methyl group. In this case, each pair of free radicals results in a pair of new end groups, one of which will involve a carbon double bond. In the presence of atmospheric oxygen the two new end groups may involve oxygen, as an aldehyde group, for example.

A major unresolved question is the extent to which free radical propagation reactions, such as those depicted in Fig. 7, produce additional chain scissions from the initial stress induced chain rupture. If a significant number of such reactions occurs a high local concentration of chain rupture will exist and these may serve as sites for microvoid formation. This situation is depicted schematically in Fig. 9 where an initial stress-induced chain rupture has initiated additional chain scissions. Even if the molecular segments cleaved by free radical attack are not load bearing at the time of the stress-induced rupture they are removed from any future load bearing role that would result from subsequent local deformation. 


\section{Viscosity - Averaged Molecular Weight}

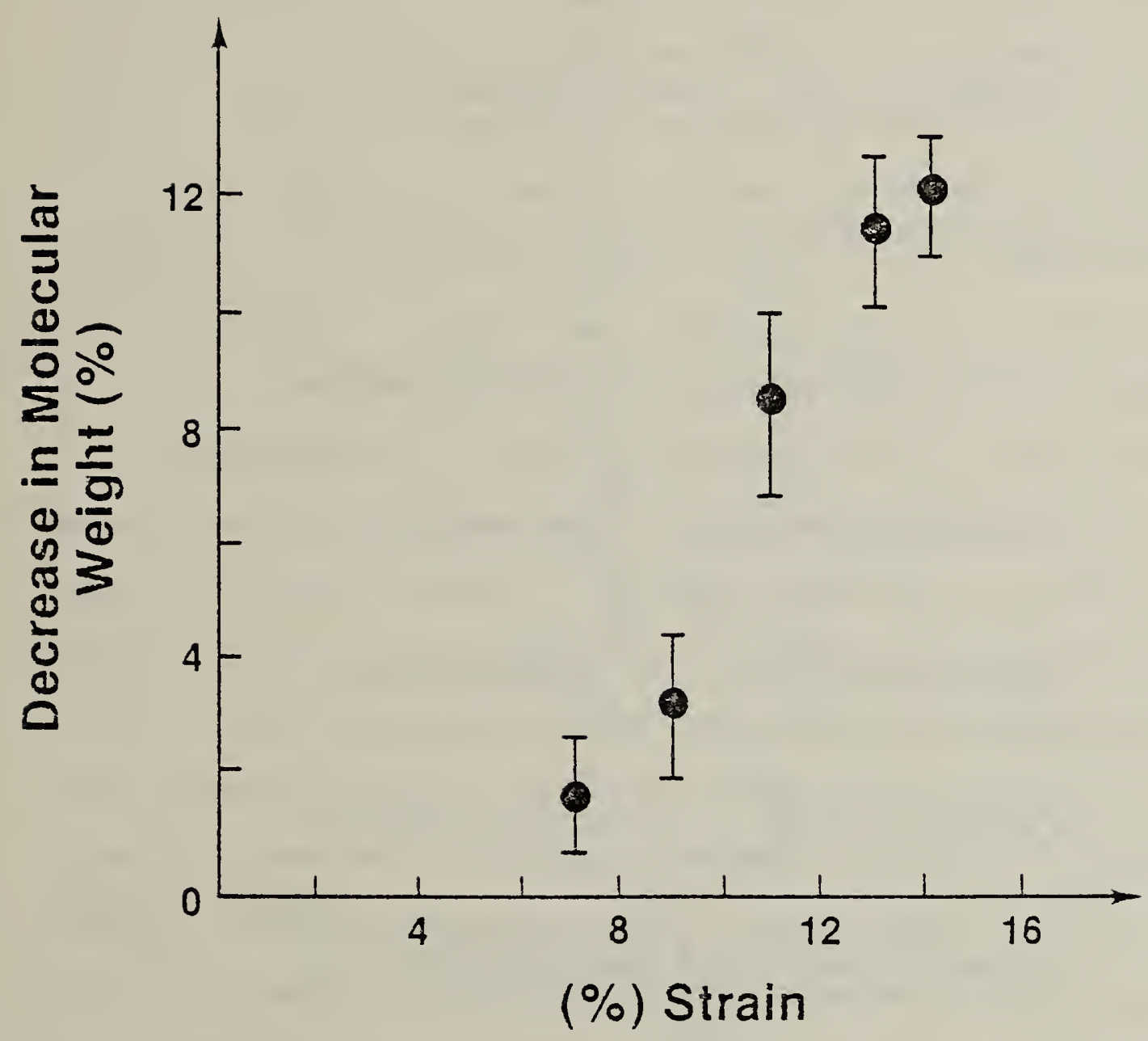

Figure $8 b$ - Degradation of the molecular weight of nylon-6 fiber by straining 
$\mathrm{CH}_{2}-\mathrm{CH}_{2}-\mathrm{CH}_{2} \sim$

NCH

$\sim_{C=C_{H}^{\prime}}^{C_{H}^{H}}$

NC:

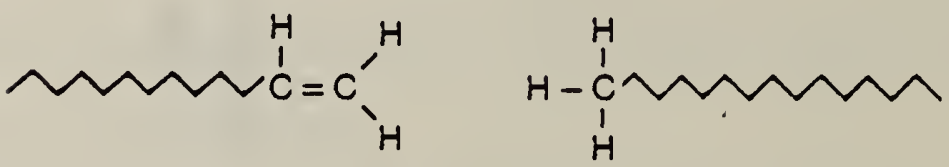

N

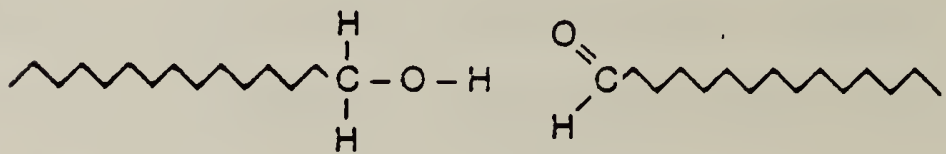

$\sim_{C_{H}^{C}-H}^{H_{H}^{H}}$

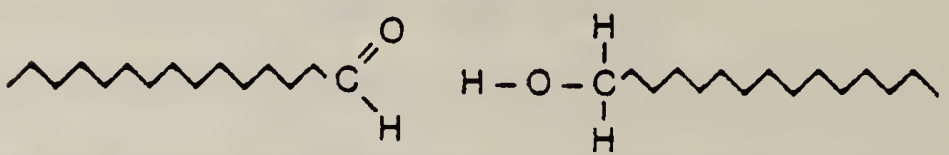

$\mathrm{CH}_{2}-\underset{\dot{H}}{\mathrm{C}}-\mathrm{CH}_{2}$

$\mathrm{CH}_{2}-\mathrm{CH}_{2}-\mathrm{CH}_{2} \sim$ 
The extent of free radical propagation reactions may be evaluated through comparison of the concentration of free radicals produced during the fracture process and the resulting number of molecular chain scissions. The latter quantity may be determined in one of two ways. The type and concentration of chemical moities at the chain ends can be determined by infrared spectroscopy. In this technique, infrared absorption bands identifiable with molecular vibrations of end groups are monitored before and after application of mechanical stress. The difference in absorption can then be related to changes in end group concentrations, and from this information the concentration of chain scission found. The infrared data may be susceptible to errors from a variety of sources. A discussion of these in light of recently reported values in the literature will be given.

A second method for estimating the concentration of chain ruptures is molecular weight degradation studies. Each chain scission lowers the average length of the chain involved. The cummulative effect is to lower the molecular weight, or more accurately, the number average molecular weight. Molecular weight and molecular weight distribution measurements are carried out on polymer solutions. Hence, these measurements are destructive as far as solid polymers are concerned. Furthermore, viscometry, the usual method of determining molecular weight, yields a measure of molecular weight that is not readily interpretable in terms of number average molecular weights, and hence concentration of chain scissions.

Zhurkov and colleagues were the first to compare ESR measurements of the number of free radicals produced by fracturing polymers with the number of chain scissions as determined by infrared spectroscopy $(1,7)$. In these studies it was reported that each free radical might represent a large number of chain scissions. In fact, the number was reported to be several 
thousand for polyethylene indicating substantially more molecular damage during fracture than generally thought (1). On the other hand, determinations of the number of chain scissions during fracture of polyethylene by viscosity average molecular weight changes yielded values three orders of magnitude lower (3). These results were reported by a different group who were using polyethylene from another source (8).

The extremely large discrepancies between data from the two measurement methods cannot be explained in terms of inherent approximations used to interpret numbers of chain scissions from viscosity average molecular weight changes. In addition, infrared and molecular weight degradation studies had not been performed on the same polymer samples so that the effects of initial molecular weight, morphology, etc. could not be adequately ascertained. Our work reported herein has included ESR, infrared spectroscopic, and molecular weight degradation measurements on the same polymer specimens. In this way, for the first time, direct comparisons can be made to evaluate the extent of free radical propagation reactions in polymer fracture and failure.

A major problem encountered in the infrared spectroscopic determination of new end group concentrations resulting from fracture has been the sensitivity of the IR measurements to factors other than concentrations of particular groups. Deforming a polymer to fracture affects sample thickness, surface conditions, transparency, degree of crystallinity, and chain orientation. A11 of these factors can affect the ir measurements thereby obscuring or exaggerating changes in end group concentrations. Although in principle it should be possible to separate the spectral changes that are a consequence of alterations in end group concentrations this has proven to be a difficult task. In our investigations we used sample preparation techniques that minimized effects from extraneous factors (9). 


\section{RESULTS}

In our research we have used the highly sensitive technique of Fourier transform infrared spectroscopy (FT-IR) to measure small changes in concentrations of end groups due to polymer fracture. The FT-IR technique is several order of magnitude more sensitive than conventional dispersive infrared techniques, and hence is ideally suited for these studies (10). Furthermore, the spectroscopic data is obtained in digital form which facilitates spectral subtraction and data analyses required to determine changes in end group concentrations. The signal-to-noise advantage of FT-IR can be utilized to extend investigations of chain scission to less severe conditions of mechanical degradation.

Polyethylene was chosen for this study because it had been used in previous studies that used conventional dispersive ir instruments, and the IR spectrum of polyethylene is relatively free of absorption bands. Commercial polyethylenes contain end groups of the kind generated during polymer fracture as a product of the polymerization process. New end group concentrations for fractured polyethylene are in the range of one per $10^{5}$ to $10^{6}$ carbon-carbon bonds. Our studies using FT-IR have indicated that concentrations of at least an order of magnitude lower than this can be observed. Ideally, one would like the initial end group concentration to be smaller than one per $10^{6}$ carbon-carbon bonds.

We have characterized the amount of chain scission in polyethylenes that have been mechanically degraded by (1) grinding under liquid nitrogen, (2) straining to fracture in tensile loading, and (3) fatiguing under cyclic loading up to and including failure. The last mentioned series of tests were carried out at 4 different peak stress levels and 3 different mechanical test frequencies. Since initial concentrations of end groups of the same order of magnitude or larger as that produced by mechanical degradation can greatly complicate the infrared spectroscopic analysis we have examined 
polyethylenes having a range of molecular weights and hence, end group concentrations. The ultra high molecular weight polyethylenes, Mw $>10^{6}$ were best suited for the FT-IR studies.

Initial FT-IR and ESR studies were carried out on commercial polyethylenes in the form of rods that were mechanically degraded by grinding under liquid $\mathrm{N}_{2}$, and oriented filaments that were strained to failure in uniaxial tension (9). IR spectra for these two polyethylenes are shown in Figs 10 and 11. In each of these figures the top trace is that of the sample, the middle trace is from the reference material, and the bottom trace is obtained by digitally subtracting the middle trace from the top trace while using the band at $1309 \mathrm{~cm}^{-1}$ as an internal standard. It is apparant from visual comparison of the top two traces of either Fig. 10 or 11 that the changes in end group concentrations are sma11. In the difference spectrum of Fig. 10 we have indicated those bands attributable to new end groups. These are due to the aldehyde group at $1735 \mathrm{~cm}^{-1}$, the methyl group at $1370 \mathrm{~cm}^{-1}$, and the vinyl group at $909 \mathrm{~cm}^{-1}$.

A complete 1ist of spectral changes are given in Table where comparisons are made with two previous reports $(7,11)$. The comparisons point to the principal cause of the unusually large concentrations of end groups previously reported (7). Note that Zhurkov et al (7) reported a significant incre in the concentration of vinylene groups $(\mathrm{RCH}=\mathrm{CHR}$ ') whereas neither our work nor that of Tabb (11) yielded any changes in this band. Unlike the polyethylene specimens used by us and Tabb those used by Zhurkov and co-workers contained a significant concentration of vinylene groups as evidence by an intense ir band at $965 \mathrm{~cm}^{-1}$ (12). We attribute the spectral changes reported by Zhurkov for the vinylene band to artifacts such as sample thickness, orientation, void formation that were accentuated by the significant absorption at $965 \mathrm{~cm}^{-1}$ in the reference material. 


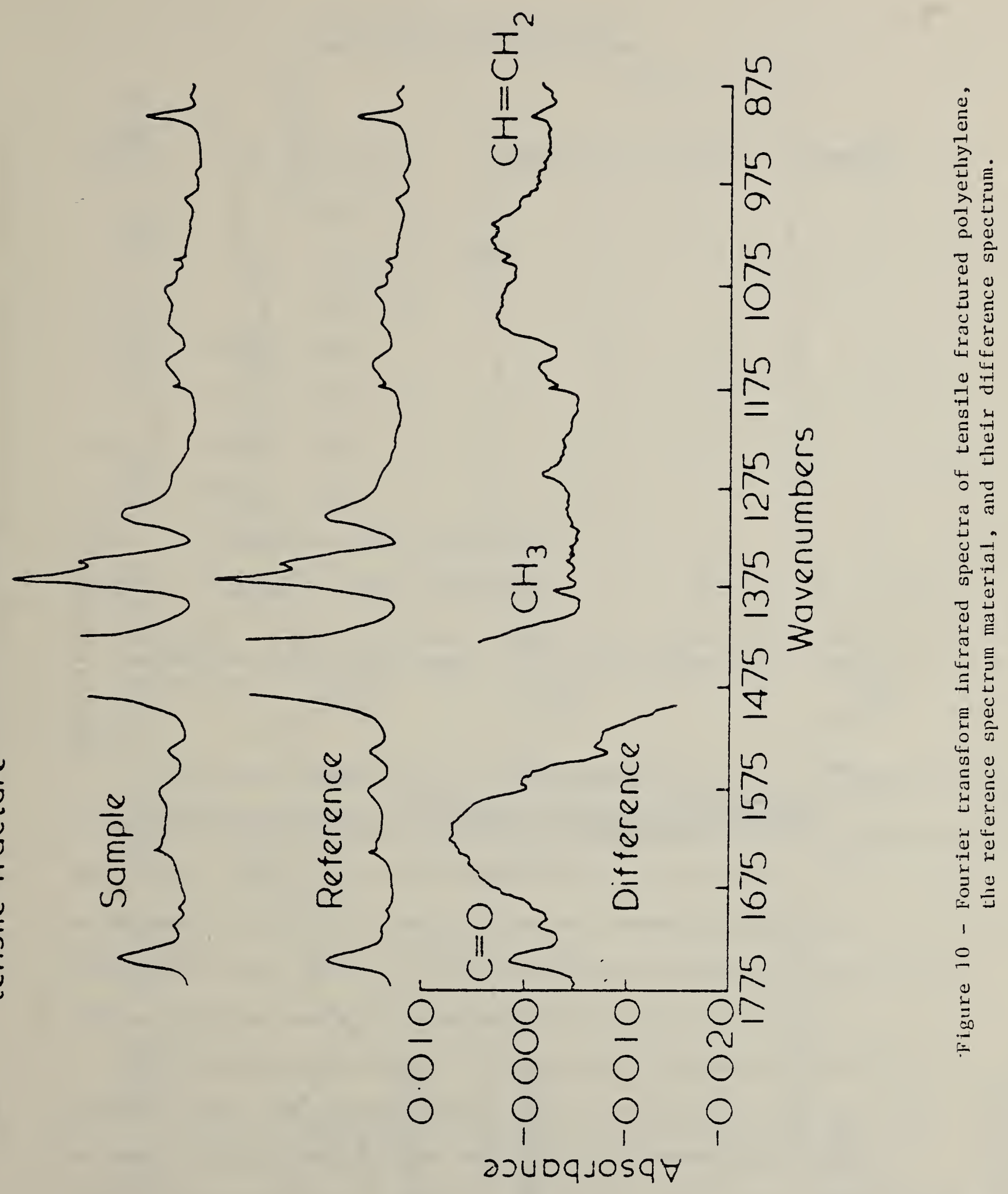




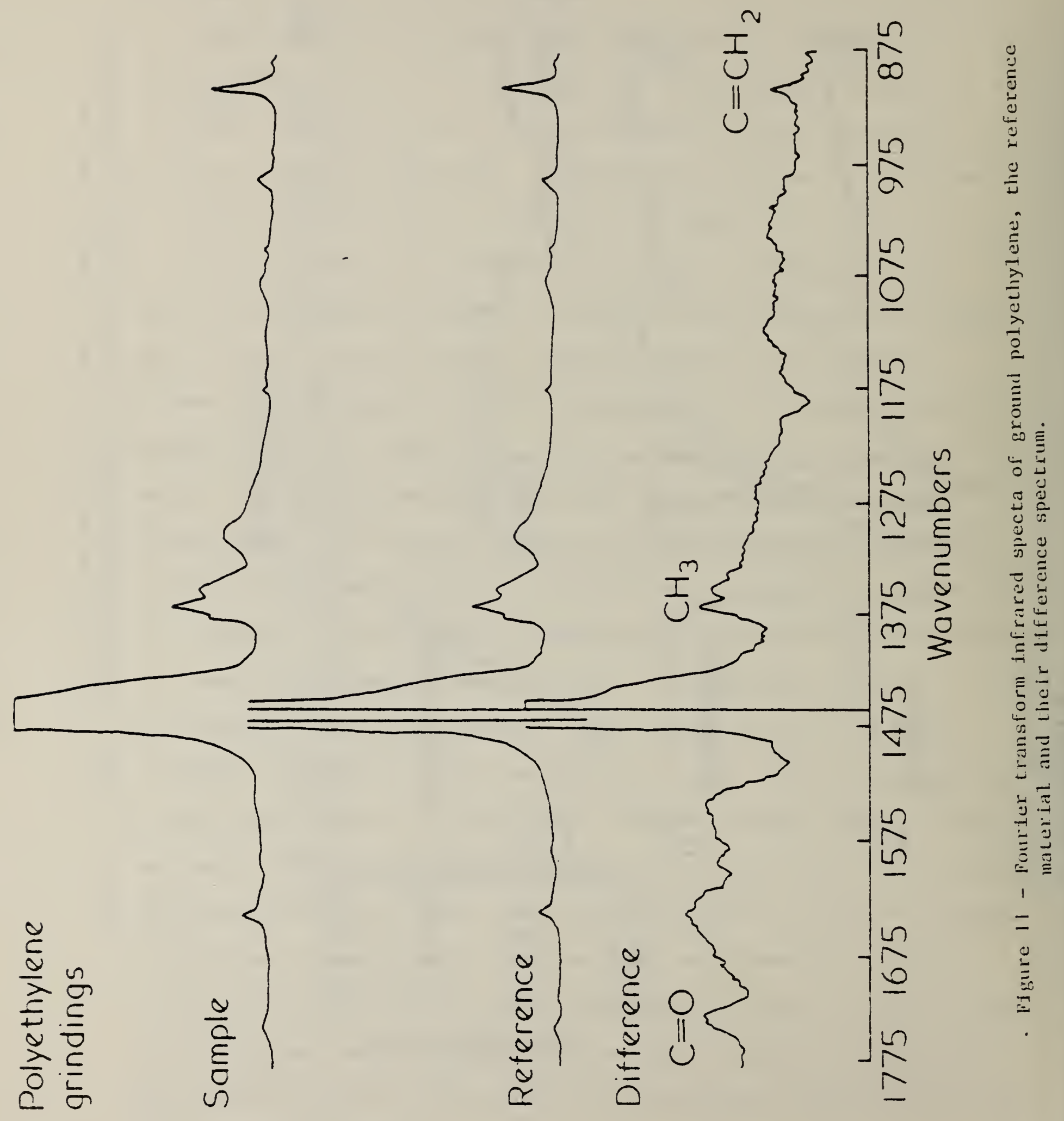




\section{TABLE 1}

IR Spectral Changes in

Tensile Fractured Polyethylene

Spectral Changes*

\begin{tabular}{|c|c|c|c|c|}
\hline $\begin{array}{l}\text { Frequency } \\
\qquad\left(\mathrm{cm}^{-1}\right)\end{array}$ & Assignment & This Work & $\begin{array}{l}\text { Zhurkov } \\
\text { Ref. } 1\end{array}$ & $\begin{array}{c}\text { Tabb } \\
\text { Ref.11 }\end{array}$ \\
\hline 909 & $\mathrm{RCH}=\mathrm{CH}_{2}$ & + & +++ & ++ \\
\hline 965 & trans $\mathrm{R} \mathrm{CH}=\mathrm{CHR}^{\prime}$ & - & + & - \\
\hline 990 & $\mathrm{RCH}=\mathrm{CH}_{2}$ & - & - & + \\
\hline 1370 & $\mathrm{CH}_{3}$ def. $\mathrm{RCH}_{3}$ & + & ++ & ++ \\
\hline 1642 & $\mathrm{C}=\mathrm{C}$ str. $\mathrm{RCH}=\mathrm{CH}_{2}$ & - & $\mathrm{NR}$ & ++ \\
\hline 1717 & $C=0$ str. $R C O R^{\prime}$ & + & + & - \\
\hline 1735 & $\mathrm{C}=0$ str. $\mathrm{RCHO}$ & ++ & ++ & + \\
\hline 1898 & Combination mode, crystalline & + & $\mathrm{NR}$ & + \\
\hline 2020 & Combination mode, crystalline & + & $\mathrm{NR}$ & +++ \\
\hline $\begin{array}{l}\text { * Magn } \\
\text { numbe } \\
\text { not }\end{array}$ & $\begin{array}{l}\text { de of change indicated by num } \\
\text { the greater the change. No }\end{array}$ & $\begin{array}{l}\text { mber of }+ \\
\text { change } i\end{array}$ & $\begin{array}{l}\text { gns, th } \\
\text { howned }\end{array}$ & $\begin{array}{l}\text { er the } \\
\text { nd NR if }\end{array}$ \\
\hline
\end{tabular}

To circumvent artifacts due to chain orientation, etc. we prepared films for ir measurements by dissolving the material to be investigated in a suitable solvent from which films were cast for infrared spectroscopic analysis. Alternately, we melt pressed films for IR spectroscopic study directly from the mechanically degraded materials. Our findings were the same with either method of specimen preparation.

A third specimen examined in our preliminary work was an ultra high molecular weight polyethylene which was also ground under liquid $\mathrm{N}_{2}$. The spectra of this polyethylene are shown in Fig. 12 where again the top trace is from the fractured material, the middle trace is from the reference, and the bottom trace is their difference. Note that there is virtually no 
Polyethylene (UHMW) grindings

Sample

Reference

$C=0$

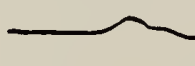

Difference

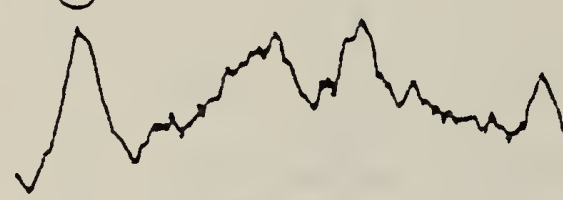

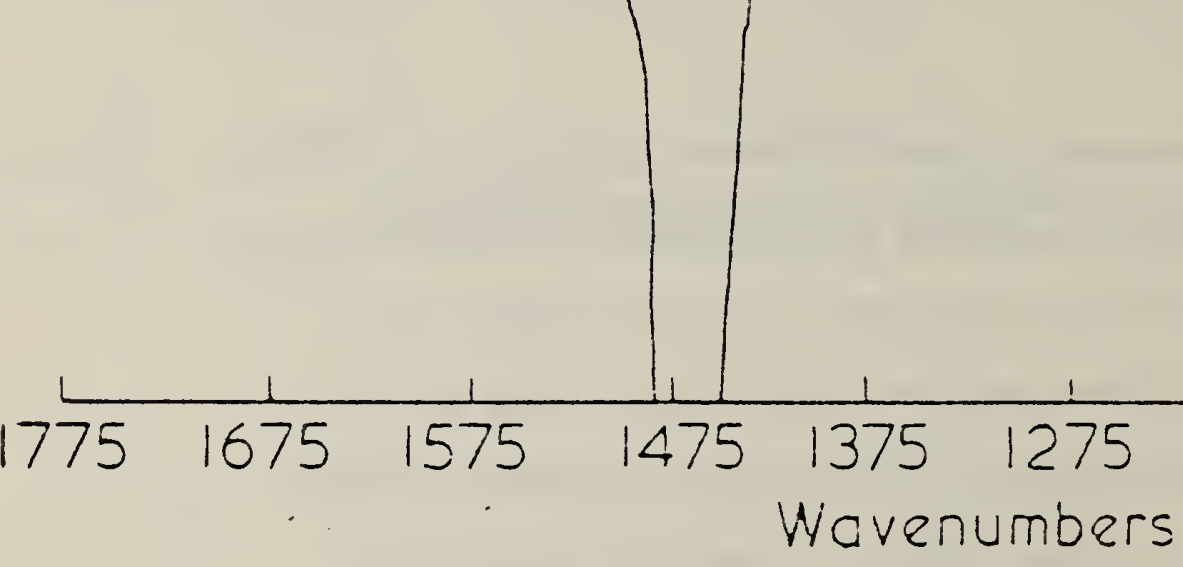

: Figure 12 - Eourier transform infrared spectra of ground ultra high molecular weight polyethylane, the reference material and their difference spectrum. 
absorption in the reference spectrum at either the aldehyde group frequency, $1735 \mathrm{~cm}^{-1}$, or the vinyl moiety frequency at $909 \mathrm{~cm}^{-1}$. Compared to the lower molecular weight polyethylenes, Figs. $10 \& 11$, ultra high molecular weight polyethylene is an excellent candidate material for spectroscopic study since small changes in end group concentrations can be more readily detected. Concentrations of new end groups attributable to mechanical degradation and determined from the difference spectrum of Fig. 10 are presented in Table 2. Integrated band intensities were determined by digital integration of the baseline corrected absorption bands. Values for absolute intensities were taken from the literature $(13,14)$, and the Beer's law relationship was assumed. The number of chain scissions was estimated from end group concentrations by summation of the number of aldehyde and vinyl groups. Each chain rupture that leads to two end groups produces one carbon double bond, as shown in Eig. 7.

\section{TABLE 2}

New End Groups Formed During Fracture of Polyethylene

$\begin{array}{lcc}\text { Group } & \begin{array}{c}\text { IR Band Freq. } \\ \left(\mathrm{cm}^{-1}\right)\end{array} & \begin{array}{c}\text { Concentrations } \\ (\text { No. } / \mathrm{cc})\end{array} \\ \mathrm{RCH}^{\prime} \mathrm{CH}_{2} & 909 & 1.3 \pm .4 \times 10^{17} \\ \mathrm{RCH}_{3} & 1370 & 7.3 \pm .4 \times 10^{17} \\ \mathrm{RCHO} & 1735 & 1.9 \pm .6 \times 10^{17}\end{array}$


The number of chain scissions per gram are listed in Table 3 where comparison is made to the number of free radicals produced during the degradation process. Ratios of these two concentrations provides a measure of the extent of free radical reactions. Values of the ratio of chain scissions to free radicals range from 11-125 depending on molecular weight and type of mechanical degradation. These numbers are much smaller, by at least a factor of 20 , than those previously reported from comparison of IR and ESR data (7). Our values are larger by 1 to 2 orders of magnitude than that reported by Stoeckel et al from viscosity-average molecular weight and ESR data on tensile fractured specimens (8).

TABLE 3

Chain Scissions per Free Radical

Ground PE

No. Chain Scissions

Per Gram

No. Free Radicals

Per Gram

Chain Scissions

Per Radical
$34-50$
UHMW

Comercial
Tensile Fractured PE

$3.4 \pm 1 \times 10^{17}$

$3.5 \times 10^{15}$

$1.2 \times 10^{16}$
$1 \times 10^{17}$

$11-13$

$1.2 \pm .1 \times 10^{18}$$$
13
$$

$68-125$
Zhurkov, et.al.

$9.9 \times 10^{18}$ $5 \times 10^{15}$

1,980

Viscosity average molecular weight measurements do not provide a direct measure of the number of chain scissions because viscosity depends on weight average rather than number average molecular weight. The analysis of changes in viscosity average molecular weight to determine number of chain scissions requires assumptions of the dependence of relative probabilities of rupture on molecular length, as well as the molecular weight distribution. 
We have used gel permeation chromatography, GPC, to determine the change in number average molecular weight with mechanical degradation. Plots of the molecular weight distributions of the tensile fractured polyethylene and the reference material are shown in Fig. 13, and the number of chain scissions deduced from these distributions are given in Table 4 along with the ratio to the number of free radicals. Unlike previous determinations the chain scission concentration determined from molecular weight changes is in good agreement with the results of the infrared data. Thus, the discrepancy between previous measurements of chain scission concentrations may have been caused by uncertainties in viscosity average molecular weight measurements, method of mechanical deformation, or, molecular weight distribution of the original material.

TABLE 4

Chain Scissions Per Free Radical

IR

$3.4 \pm 1 \times 10^{17}$

$3.5 \times 10^{15}$

$68-125$

GPC

$\begin{array}{lcc}\begin{array}{l}\text { No. Chain Scissions } \\ \text { Per Gram }\end{array} & 3.4 \pm 1 \times 10^{17} & 5.4 \times 10^{17} \\ \begin{array}{l}\text { No.Free Radicals } \\ \text { Per Gram }\end{array} & 3.5 \times 10^{15} & 3.5 \times 10^{15} \\ \begin{array}{l}\text { Chain Scissions } \\ \text { Per Radical }\end{array} & 68-125 & 154\end{array}$

Zhurkov and co-workers (1) examined the mechanisms leading to the development of microvoids in stressed polymers by comparing the number of free radicals 


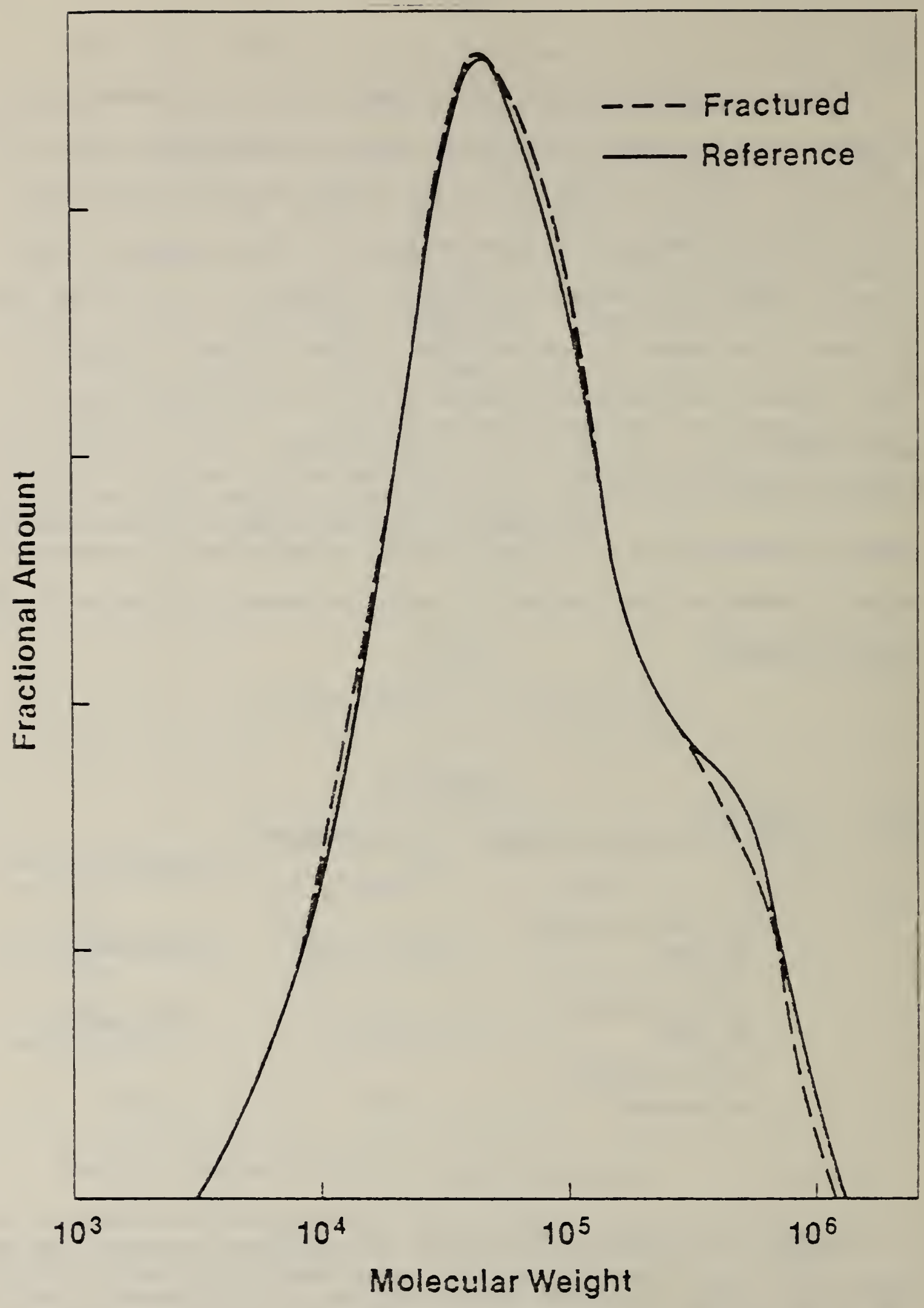

\footnotetext{
'Eisure 13 - Molecular weight distribution of tensile Eractured polyethylene and its reference tateriai.
} 
produced during mechanical degradation with the concentration of chain scissions and the size and concentration of microvoids generated. The microvoid concentration and size were deduced from small angle x-ray scattering data using a two-phase model - polymer and microvoid. It was reported that the number of microvoids was approximately equal to the number of free radicals, and that the average cross-sectional area of the microvoids was consistent with the product of the number of chains ruptured per free radical and the cross-sectional area per chain. Thus, their data suggested a model in which one microvoid is generated per mechanically-induced free radical and the size of the microvoid is controlled by the number of chain scissions produced per mechanically generated free radical.

In light of our finding that the number of chain scissions produced in tensile fracture polyethylene per radical is lower by at least an order of magnitude we are planning to carry out $x$-ray scattering studies on our samples. In analyzing the small angle $x$-ray data we will assume a three phase system - crystalline, amorphous, and microvoid, instead of the two phase system used by Zhurkov. The mathematical equations for a three component system has been worked out and applied to a particulate composite assumed to be composed of polymer, particulate reinforcement, and voics (15). FATIGUE OF ULTRA HIGH MOLECULAR WEIGHT POLYETHYLENE

The second aspect of our work in this contract period has been concerned with investigating the relationship between growth in the chain scission concentration with the state of mechanical damage and whether failure could be associated with a critical concentration of chain scissions. This work was carried out on ultra high molecular weight polyethylene in orcer to take advantage of the initial low concentration of end groups in these materials. 
Mechanical degradation was controlled in uniaxial fatigue tests in which both frequency of the applied load and its peak value were varied to obtain failure times over several decades. The applied stress was of the form

$$
\sigma(t)=A(1+\sin \omega t)
$$

so that the applied stress varied from zero to $2 \mathrm{~A}$. The mechanical testing results are sumarized in Figs. $6 a \& b$ in which it is seen that time-to-failure of a particular test frequency can vary from one to two orders of magnitude depending on peak stress.

In equation 2 a relationship is derived between the time to failure and a critical concentration of chain ruptures. In the additivity of damage concept the amount of damage in a material increases in time at a rate determined by the applied stress and temperature. At a particular stress level, the fractional damage is given by the ratio of the time the specimen is held at that stress to the time it would take the specimen to fail at the same stress level. The latter times-to-failure are determined in dead load tests. From the dead load failure times the times-to-failure under cyclic loading conditions can be found and these are compared to experimental fatigue data in Fig. 6. It is seen in Fig. 6 that the experimental failure times are significantly higher than the predicted times which raises questions concerning the notion of a critical concentration of chain ruptures determining failure, the additivity of damage concept, or both.

We have examined the concept of failure associated with a critical concentration of chain scissions by determining the amount of chain scission at failure for polyethylene specimens fatigued to failure at different peak stresses and that exhibited quite different failure times. 
The spectrum of an ultra high molecular weight polyethylene fatigued to failure at $0.002 \mathrm{~Hz}$ is shown in Fig. 14 along with that of the reference material and their difference. Both aldehyde and methyl end groups have increased in concentration, and consistent with the findings on ground ultra high molecular weight polyethylene, virtually no increase in vinyl group concentration has been detected. The chain scission concentrations are found from the integrated intensities of the aldehyde group band at $1735 \mathrm{~cm}^{-1}$. The difference spectra from specimens fatigued to failure at peak stresses of 35 to $45 \mathrm{MPa}$ are shown in Fig. 15. The areas of these peaks are virtually the same even though times to failure varied by almost a factor of 20. The concentrations found from these peaks are given in Table 5, and their equality is indicative of failure at a critical concentration of chain scissions.

\section{TABLE 5}

Fatigue of Ultrahigh MW Polyethylene

\begin{tabular}{cccc} 
Peak Stress (MPA) & & \multicolumn{2}{c}{ Concentration } \\
\cline { 2 - 3 } 30 & $\frac{\mathrm{C}=0}{1.95 \times 10^{18}}$ & $\frac{\mathrm{RCH}=\mathrm{CH}_{2}}{-}$ \\
35 & $1.82 \times 10^{18}$ & $3 \times 10^{16}$ \\
40 & $2.03 \times 10^{18}$ & - \\
45 & $1.97 \times 10^{18}$ & $1 \times 10^{16}$
\end{tabular}

Spectroscopic investigations have been carried out on a second ultra high molecular weight polyethylene with a manufacturer's reported molecular weight that was one-half the value of the material used in the aforementioned study. For this material it was found that failure occur at a mechanically induced chain rupture concentration of about $1 * 10^{18} / \mathrm{gram}$ instead of $2 * 10^{18} / \mathrm{gram}$. This finding further suggests that molecular weight is a determining factor in the level on molecular damage that can be tolerated before failure occurs. 


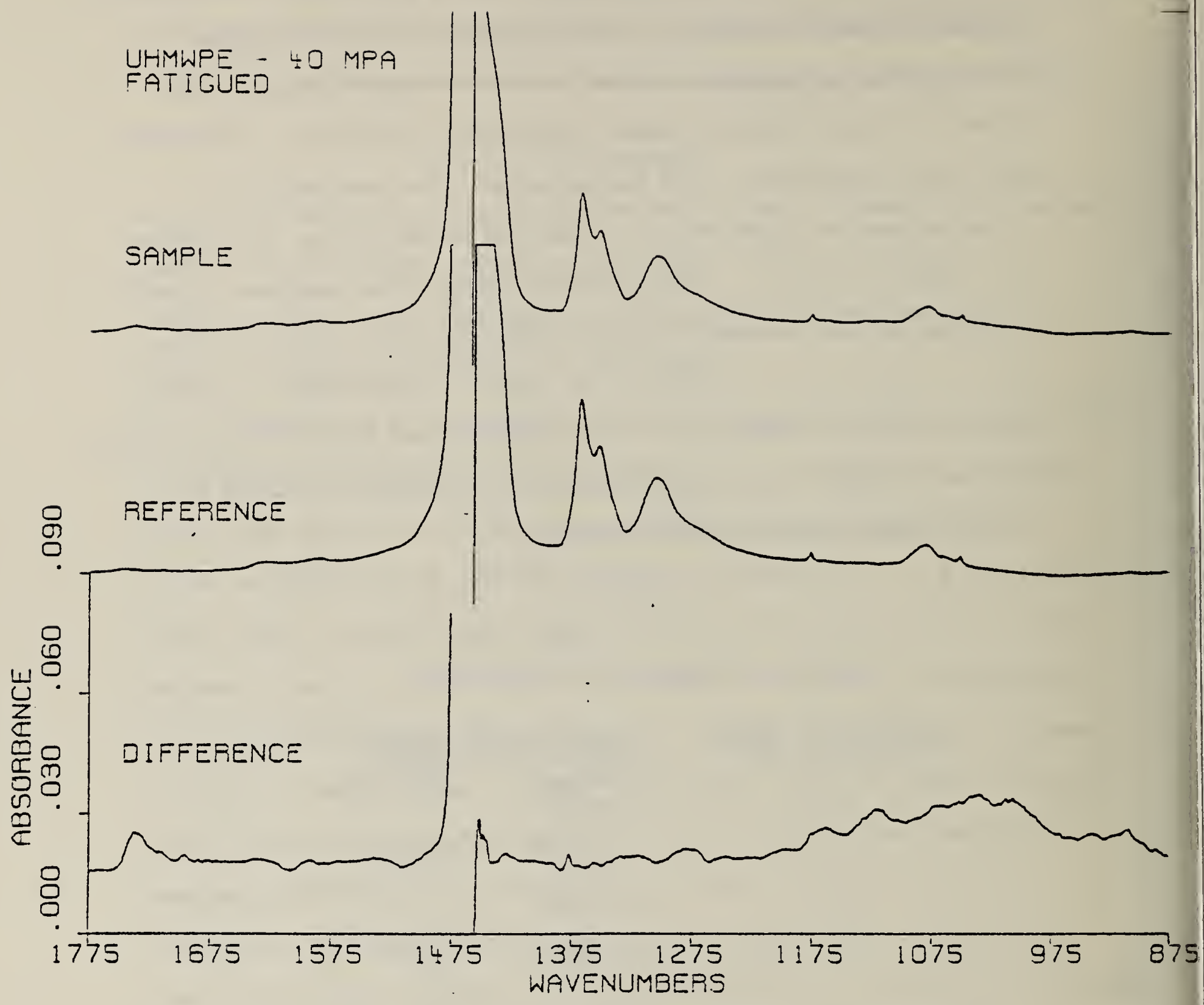

Figure 14 - IR spectra of ultra high molecular weight polyethylene fatigued to failure at $0.002 \mathrm{~Hz}$ and a peak load of $40 \mathrm{MPa}$, its reference material, and the difference spectrum. 


\title{
STRESS LEVEL
}

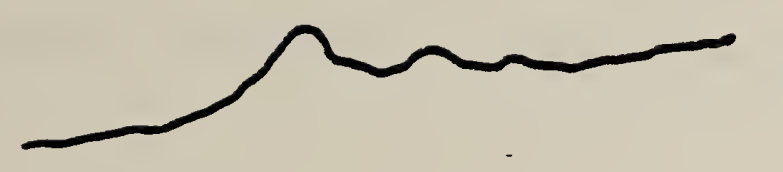

\author{
45 MPA
}
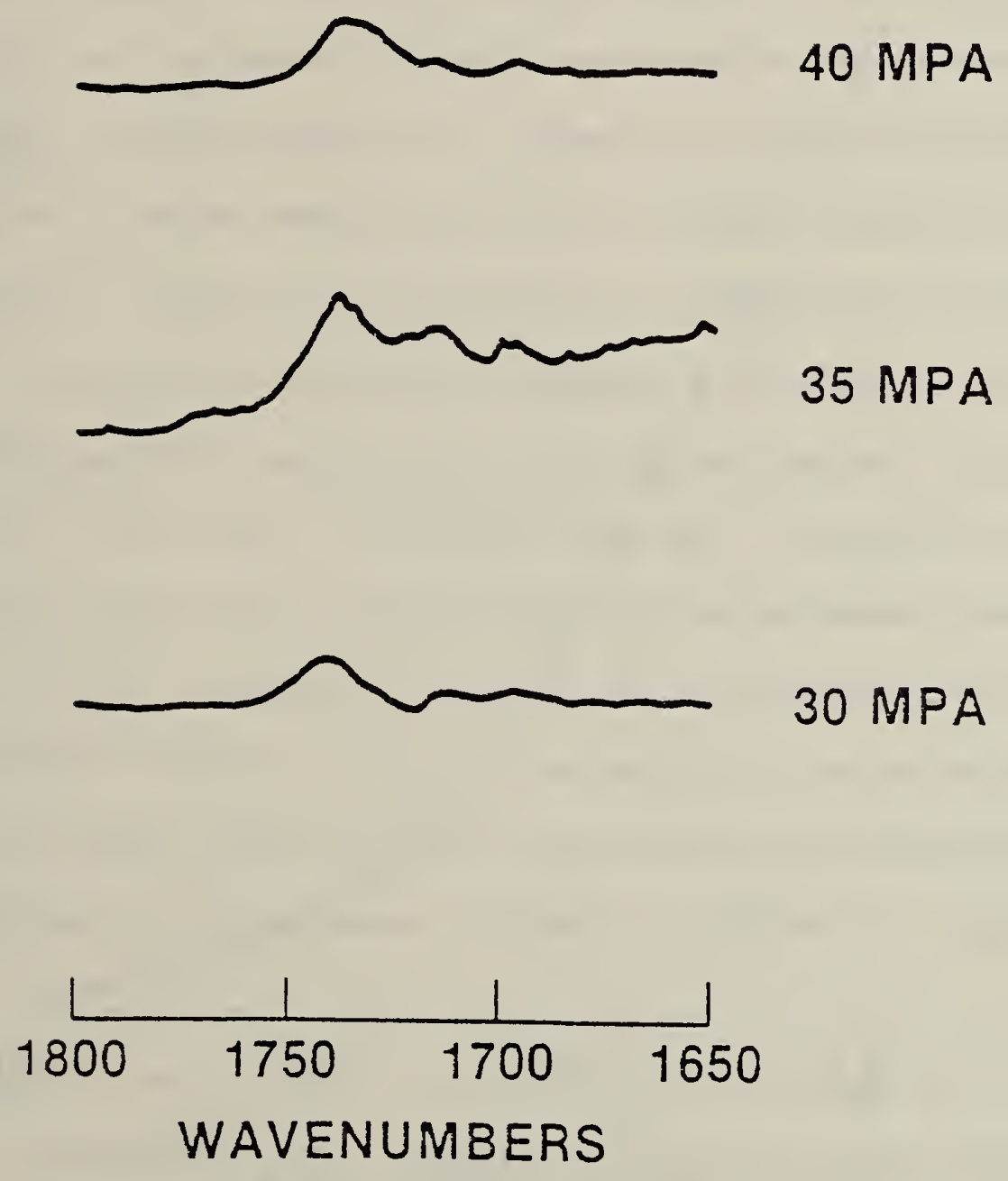

Figure 15 - Difference spectra due to aldehyde groups obtained from ultra high molecular weight polyethylene fatigued to failure at $0.002 \mathrm{~Hz}$ and at the peak stresses indicated. 
Our finding that macroscopic failure occurs at a critical concentration of chain ruptures suggests that monitoring the buildup in end group concentrations may serve as the basis for lifetime prediction. In order to fully assess the potential of this approach we have examined the increase in chain scission concentration during the course of a fatigue-to-failure test.

In this experiment the test specimen was subjected to a predetermine number of stress cycles, removed from the mechanical tester, and placed in the interferometer for infrared spectroscopic analysis. The specimen was then returned to the mechanical tester for another series of stress cycles, and the entire process repeated until the specimen failed. The increase in aldehyde group concentration as a function of the number of stress cycles is shown in Figs. 16ab for a specimen fatigued at $0.002 \mathrm{~Hz}$ and at a peak stress level of $35 \mathrm{MPa}$. During the initial stress cycles the aldehyde concentration increased only slightly. This was followed by a rapid rise to about $60 \%$ of the aldehyde concentration at failure after which it rose linearly with the number of stress cycles until macroscopic failure. In Figs. 16ab the aldehyde concentration is plotted as its ratio to that at failure. A total of three specimens were examined under identical test conditions, and all displayed similar dependence of aldehyde concentration on number of fatigue cycles.

We have also investigated the effect of fatigue test frequency on the concentration of chain scissions at failure. These results are sumarized in Fig. 17 for the lower molecular weight ultra high molecular weight polyethylene. The weak dependence on test frequency may be caused by a slight rise in sample temperature as the fatigue frequency increases. A1though according to equation 1 the probability of chain rupture increases with increasing temperature the critical concentration would also be expected 


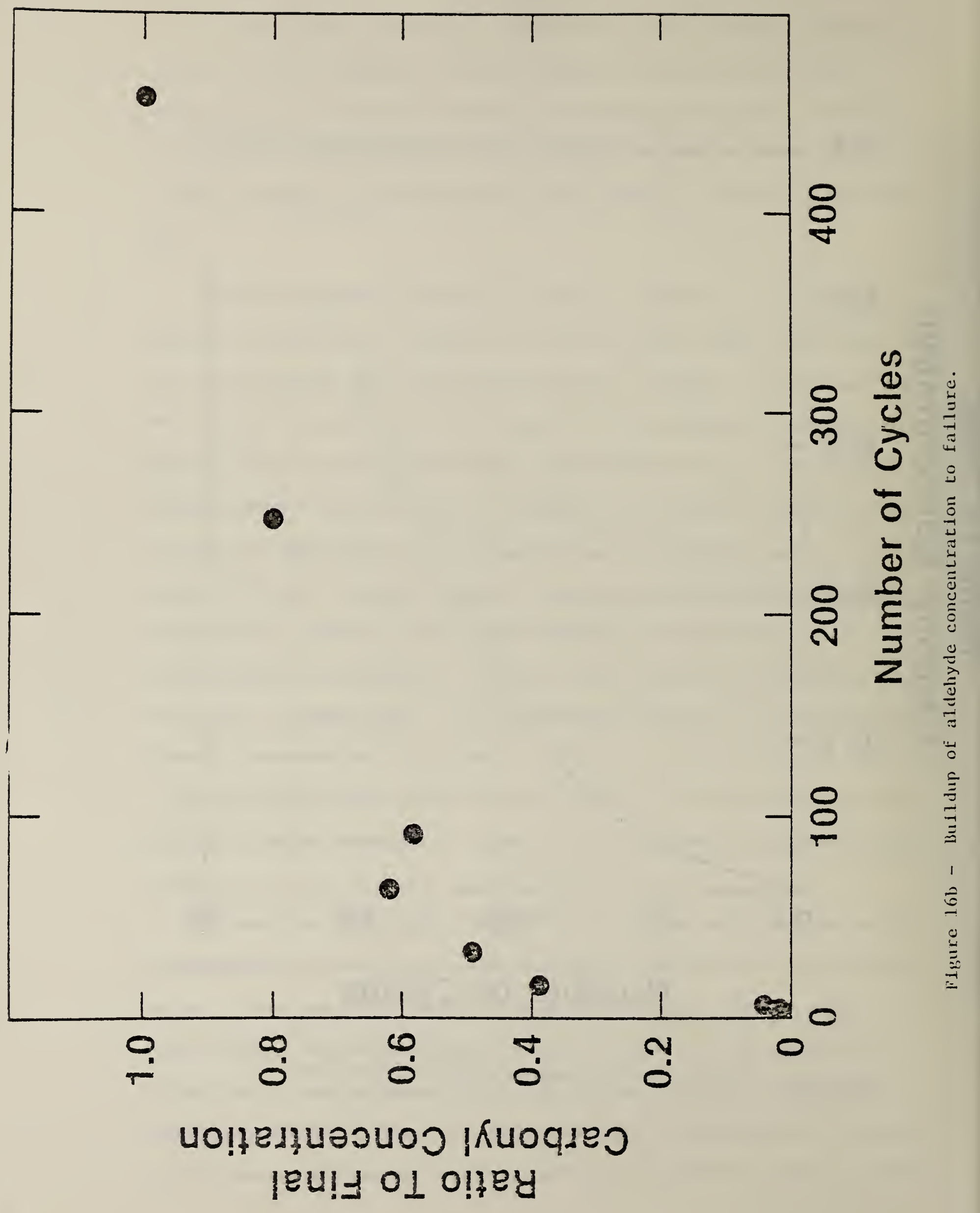




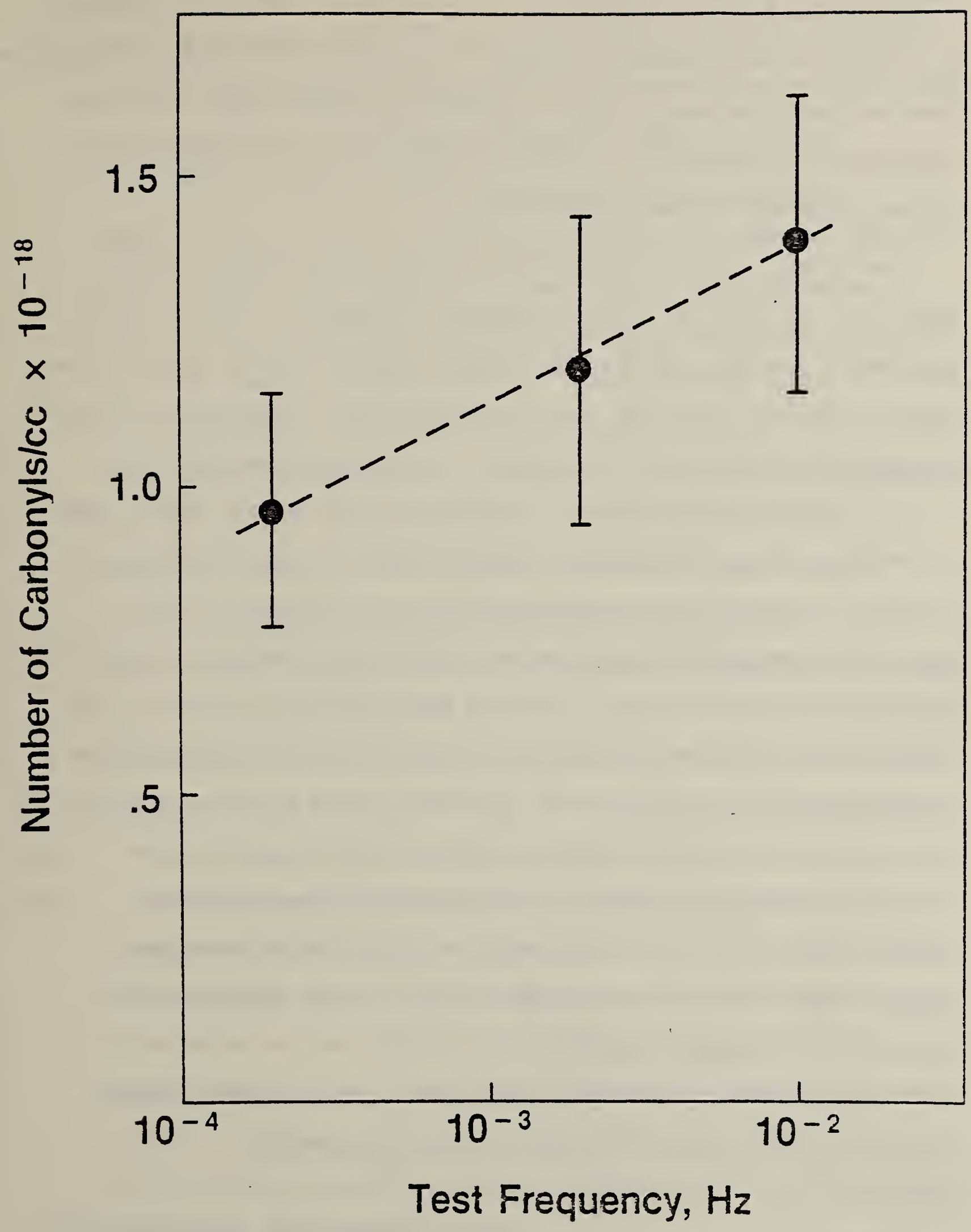

IFigure 17 - Aldehyde group concentration at failure as a function of fatigue test frequency. Peak stress level was $35 \mathrm{MPa}$. 
to rise due to a greater probability for free radical termination reactions as a result of more molecular mobility. The extent of free radical propagation reactions would decrease at higher temperatures forming damage zones that would not be of sufficient dimensions to coalesce into the microvoids that are the precursors to macroscopic failure.

The growth in the aldehyde concentration with the number of stress cycles has also been measured for specimens fatigued at $0.01 \mathrm{~Hz}$. These experiments yielded a similar behavior with number of stress cycles as that shown in Fig. 16b. Thus, the general features of the rise in chain scission. concentrations appear to be independent of the fatigue test frequency.

The fatigue experiments that have been carried out are constant peak stress tests. During the fatigue expriment the initially isotropic test specimen is elongated and preferential chain axis orientation in the direction of the applied stress occurs. The sample morphology is transformed from spherulitic texture, Fig. Ib to the fiber morphology of Fig. 2. The number of highly stressed molecules would be expected to change as these morphological changes occur. Thus, the rise in chain scission concentrations may correlate more directly with the imposed strain than the number of stress cycles in a fatigue experiment. Furthermore, the behavior of chain scission concentration with the first few cycles in fatigue (Fig.16a) is very similar to the strain induced buildup in free radical concentration or degradation of molecular weight.

Future work will address the relationship between chain scission concentration and strain in a stress relaxation experiment. CONCLUSION

Three important aspects of molecular processes associated with polymer fracture have been investigated. Detailed experiments combining ESR measurements of free radicals concentrations, infrared spectroscopic determinations of new end group formation, and GPC measurements of molecular 
weight degradation have been carried out on tensile fractured polyethylene. Excellent agreement has been found between the number of chain scissions associated with mechanical degradation as determined by increases in end group concentrations and by the change in molecular weight. When the concentration of chain scissions is ratioed to the concentration of free radicals it is found that each free radical produces an additional 100-150 chain scissions. This high local concentration of chain scissions is thought to be the precursor to microvoid formation from which macroscopic cracks that lead to failure originate. Future experiments will use small angle $x$-ray scattering to measure the size and concentration of these microvoids. Previous work had suggested that the number of microvoids should approximately equal the number of free radicals and the size of the microvoids should relate to the number of chain scissions produced per free radicals.

The second aspect of our present work has examined the effect of molecular weight and test frequency on the critical concentration of chain ruptures at macroscopic failure in a fatigue test. It was observed that decreasing the molecular weight by a factor of 2 decreased the critical concentration by a factor of 2 also. The concentration of chain scissions at failure increased slightly with increasing frequency.

The third aspect concerned an investigation of how the end group concentration, or chain scission concentration, builds up during fatigue. It was found that after a slow rise during the initial few stress cycles, the concentration grew rapidly to about $60 \%$ of its value at failure. After the abrupt rise the concentration increased linearly with the number of fatigue cycles until failure. It is concluded that monitoring the number of chain scissions through infrared spectroscopy may be a useful procedure for estimating the remaining lifetime. 



\section{References}

1. S. N. Zhurkov, V. A. Zakrevskii, V. E. Korsukov, and V. S. Kuksenko, Sov. Phys. Solid State, 13, 1680 (1973).

2. "Developments in Polymer Fracture-1", E. H. Andrews, Editor, Applied Science Publishers, London 1979.

3. V. M. Voroboyev, I. V. Razumovskaya, and V. I. Vettegren, Polymer, 19, 1267 (1978).

4. J. M. Crissman, F. A. Khoury, and G. B. McKenna, NBSIR 82-2493, U.S. Department of Commerce, National Bureau of Standards, 1981.

5. G. B. McKenna and R. W. Penn, Polymer 21, 213 (1980).

6. T. Kawashuna, S. Shimada, H. Kashiwabara, and J. Sohma, Poly. J., $\underline{5}$, 135 (1973)

7. S. N. Zhurkov and V. E. Korsukov, J. Polym. Sci. Polym. Phys. Ed 12, 385 (1974).

8. T. M. Stoecke1, J. Blasius, and B. Crist, J. Polym. Sci. Polym. Phys. Ed. 16, 485 (1978).

9. B. M. Fanconi, K. L. DeVries, and R. H. Smith, Polymer 23, 1027 (1982).

10. R. J. Bell, Introductory Fourier Transform Spectroscopy, Academic Press, New York, 1972.

11. D. L. Tabb, PhD Thesis, 1974, Case Western Reserve University.

12. V. E. Korsukov, V. I. Vettegren, and I.I. Novak, J. Polym. Sci. Symposium No. 42, 1299 (1973).

13. H. S. Wexler, Spectrochim. Acta 21, 1725 (1965).

14. V. I. Vakhlyueva, A. G. Finkel, L. M. Sverdlow and A. I. Andreeva, Opt. Spectrosc., 25, 234 (1968).

15. W-L. Wu, Polymer, 23, 1907 (1982). 

NBS-114A (REV. 2-80)

U.S. DEPT. OF COMM.

BIBLIOGRAPHIC DATA

SHEET (See instruction s)

1. PUBLICATION OR
REPORT NO.
NBSIR 83-2682.

2. Performing Organ. Report No 3. Publication Date

NBSIR 83-2682.

April 1983

4. TITLE AND SUBTITLE Annual Report to Defense Advanced Research Project Agency, Covering Period 8/1/82-12/31/82, Molecular Processes Affecting Mechanical Failure of Polymeric Materials.

5. $\operatorname{AUTHOR}(S)$

Dr. Bruno M. Fanconi

6. PERFORMING ORGANIZATION (If joint or other than NBS, see instructions)

NATIONAL BUREAU OF STANDARDS

DEPARTMENT OF COMMERCE

WASHINGTON, D.C. 20234

7. Contract/Grant No.

ARPA 4609

8. Type of Report \& Period Covered Annual

$8 / 1 / 82-12 / 31 / 82$

9. SPONSORING ORGANIZATION NAME ANC COMPLETE ADDRESS (Street, City, Stete, ZIf)

10. SUPPLEMENTARY NOTES

$\square$ Document describes a computer program; SF-185, FIPS Software Summary, is attached.

11. ABSTRACT (A 200-word or less foctual summory of most significant information. If document includes a significant bibliography or literoture survey. mention it here)

Preliminary observations have established correlations between the buildup in the concentration of molecular end groups and macroscopic failure in polymers. Current work has examined the effects of stress history, molecular weight and the dependence of the growth in end group concentrations with time during the course of a mechanical degradation experiment. In cyclic fatigue under uniaxial loading conditions the concentration of end groups was found to exhibit a sigmoidal dependence on the number of cycles. After an initial rapid use to about $60 \%$ of its value at failure the number of chain scissions was observed to increase linearly until sample failure. Such a relationship holds promise as the basis of methods to predict mechanical failure. The effects of frequency, peak stress, and molecular weight have also been examined and are reported.

12. KEY WORDS (Six to twelve entries; alphabetical order; copitalize only proper nomes; and seporate key words by semicolons) infrared spectroscopy, chain scission, polyethylene, mechanical degradation,molecular weight.

13. AVAILABILITY

Unlimited

$\square$ For Official Distribution. Do Not Release to NTIS

Order From Superintendent of Documents, U.S. Government Printing Office, Washington, D.C. 20402.

-X Order From National Technical Information Service (NTIS), Springfield, VA. 22I6I

14. NO. OF

PRINTED PAGES

46

15. Price

$\$ 8.50$ 


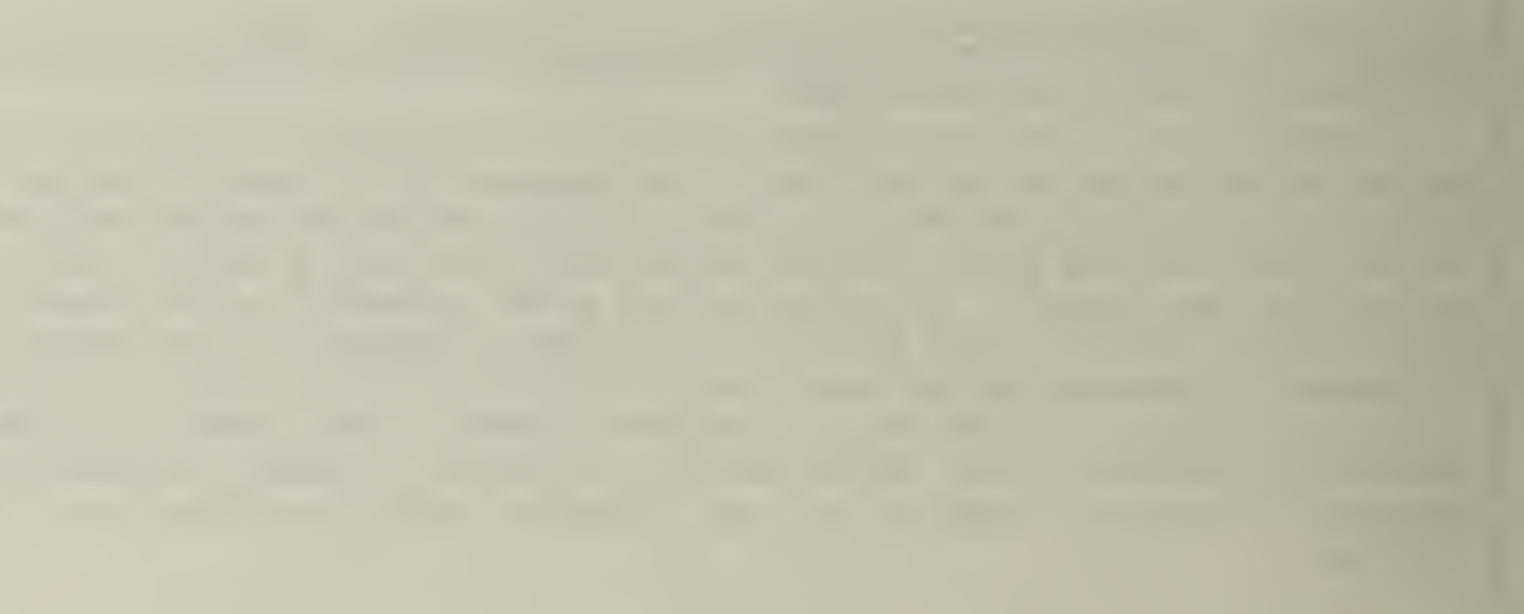

